FORWARDING FASHION: DEVELOPING AN APP TO CONTEMPORIZE FASHION DESIGN ASSESSMENT AND FEEDBACK IN HIGHER EDUCATION

\author{
by
}

\title{
Glynis Dupuis
}

Chartered Professional Accountant, CPA of Ontario, June, 2013. Bachelor of Applied Arts, Apparel Design, Ryerson University, 1994

\author{
A Major Research Project \\ presented to Ryerson University \\ in partial fulfillment of the \\ requirements for the degree of \\ Master of Arts \\ in the Program of \\ Fashion
}

Toronto, Ontario, Canada, 2019

(C) Glynis Dupuis, 2019 


\section{AUTHOR'S DECLARATION FOR ELECTRONIC SUBMISSION OF A MRP}

I hereby declare that I am the sole author of this MRP. This is a true copy of the MRP, including any required final revisions.

I authorize Ryerson University to lend this MRP to other institutions or individuals for the purpose of scholarly research.

I further authorize Ryerson University to reproduce this MRP by photocopying or by other means, in total or in part, at the request of other institutions or individuals for the purpose of scholarly research.

I understand that my MRP may be made electronically available to the public. 


\title{
FORWARDING FASHION: DEVELOPING AN APP TO CONTEMPORIZE FASHION DESIGN ASSESSMENT AND FEEDBACK IN HIGHER EDUCATION
}

Glynis Dupuis

Master of Arts in Fashion

Ryerson University, 2019

\begin{abstract}
There is a need to evolve the current collective praxis for providing assessment and feedback on creative projects within fashion and related domains in higher education (HE) programs. Rapid advancements and disruption taking place within fashion and related creative industries signal a need for graduates who can think more divergently, while the increased diversity among current and future cohorts in HE who have different learning requirements, along with faculty facing increased time constraints and limitations in their work processes, call for new methods for providing assessment and feedback efficiently and effectively. This study proposes a practical prototype of a mobile technological solution that could help to contemporize current praxis, and may contribute to the emerging field of research: Mobile-Based Assessment (MBA).
\end{abstract}




\section{Acknowledgements}

I would like to express my sincere thanks to those who supported me in this research journey: my supervisor Dr. Richard Lachman, for his great insights and dedicated support; my second reader Grahame Lynch, for helping to steer this project in the right direction; Dr. Sandra Tullio-Pow, for her support and valuable tips along the way; Ryerson's newly established CoLab, for providing me with essential support to my technological research; and to all of the interviewees who generously shared their time and experiences, and who exhibited a genuine passion for improving our collective praxis.

I would also like to extend my sincere thanks and love to my very patient family, who has supported me through demanding educational pursuits on top of my day-job since our children were born. 


\section{Table of Contents}

Author's Declaration for Electronic Submission of a MRP ................................ ii

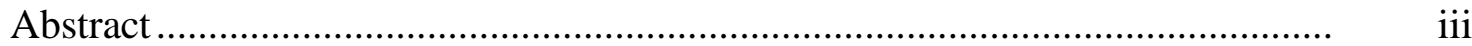

Acknowledgements ................................................................................ iv

List of Tables .................................................................................... vii

List of Figures ........................................................................................ viii

List of Appendices ............................................................................... ix

CHAPTER 1: INTRODUCTION .............................................................

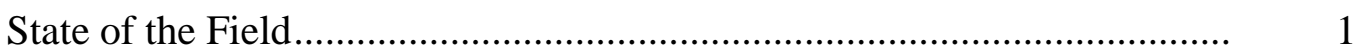

Research Aims for This Study.................................................................. 2

CHAPTER 2: LITERATURE REVIEW ………………………………….....

Slow Adoption for the Use of Technology in Assessment Design in HE and the Emerging Research Area of MBA ............................................. 3

Assessing Creativity Using the Creative Assessment Technique ............... 4

The Importance of Feedback in the HE Learning Process .......................... 4

Large Differences in Millennial Learners and the Need for Universal Instructional Design in Assessment Design ........................................... 5

State of the Fashion Design Industry: Demand for Divergent Thinking..... 6

CHAPTER 3: CONTEXTUAL REVIEW ...................................................... 7

Competitive Products in the Marketplace ................................................... 7

Learning Management System Assessment Tools ....................................... 7

CHAPTER 4: METHODOLOGY …............................................................... 9

Research Design: Practice-Based Participatory Action Research Utilizing

Design Thinking Approach................................................................ 9

Theoretical Approach ………………………………………….............. 9

CHAPTER 5: METHODS ………...................................................... 11

In-Depth Qualitative Interviews ............................................................. 11

In-Depth Faculty Interviews .............................................................. 11

In-Depth Past-Student Interviews .................................................... 12

Thematic Analysis of In-Depth Interview Data …………….................... 12

Define App Architecture Using Design Thinking Approach ...................... 12

Qualitative Interviews: User-Feedback Sessions ........................................ 13

Design Thinking Iterative Process: App Development .................................. 13

Preliminary User-Testing Session ............................................................. 14

Finalize Design of App Prototype ............................................................ 14 


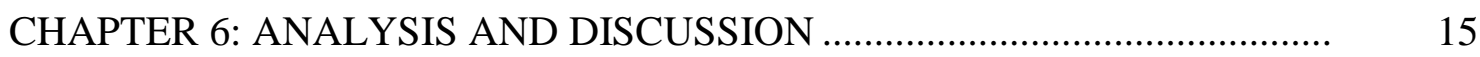

Qualitative Interview Findings ....................................................... 15

Faculty Interviews.............................................................. 15

Student Interviews................................................................... 19

Summary of Interview Findings ................................................ 22

Features Inclusion......................................................................... 22

Features Directive ................................................................. 22

Features List..................................................................... 23

Proposed Design ................................................................................. 27

Development of Pre-Designed Templates ..................................... 31

Preliminary User-Testing/Feedback Sessions............................... 34

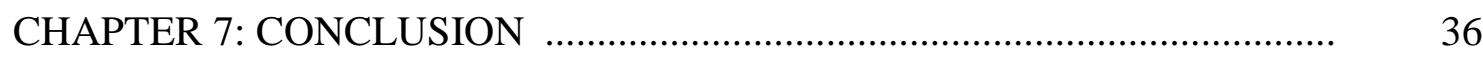

Study Findings and Contributions ........................................................ 36

Limitations in Scope of Study .............................................................. 37

CHAPTER 8: FUTURE DIRECTIONS …............................................... 38

Appendix A: Excel Breakdown of Initial App Architecture ............................. 39

Appendix B: Example of Function Breakdown in Excel.................................. 40

Appendix C: Screenshot of Early Design Stages in Adobe XD .......................... 41

Appendix D: Designgrade Prototype Screens ............................................... 42

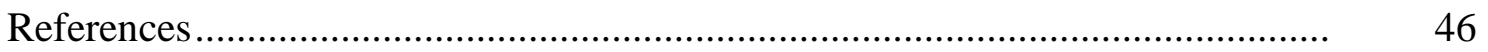




\section{List of Tables}

$\begin{array}{lll}\text { Table } & \text { Page }\end{array}$

1. App Features List With Description and Value Offering......................... 24 


\section{List of Figures}

$\begin{array}{lll}\text { Figure } & \text { Page }\end{array}$

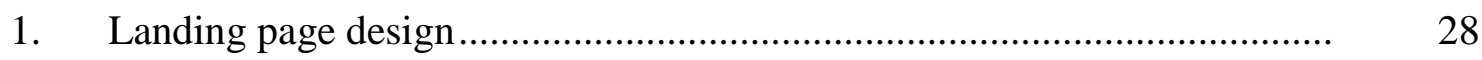

2. Main working page ........................................................................... 28

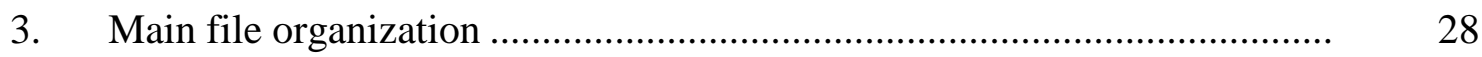

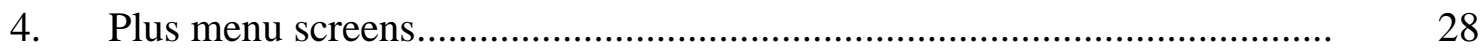

5. Comment chooser roller-scroll .......................................................... 29

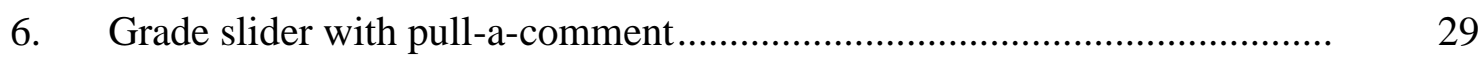

7. Part of the work flow prompts in setting up grade criteria boxes ............... 30

8. Draw/scribble function used on main screen........................................... 31

9. Example of drawing over artifact image ............................................. 31

10. Example of student-facing PDF output from one of Designgrade's pre-designed templates ................................................................. 33 


\section{List of Appendices}

$\begin{array}{ll}\text { Appendix } & \text { Page }\end{array}$

A. Excel Breakdown of Initial App Architecture ........................................ 39

B. Example of Function Breakdown in Excel............................................ 40

C. Screenshot of Early Design Stages in Adobe XD .................................... 41

D. Designgrade Prototype Screens ........................................................ 42 


\section{CHAPTER 1: INTRODUCTION}

\section{State of the Field}

The fashion industry has been experiencing a dramatic evolution in the wake of the continued globalization of the economy, along with disruption from emerging digital technologies, geopolitical influences, and structural changes triggered by ignited environmental concerns (Brydges, Hracs, \& Lavanga, 2018; The Business of Fashion and McKinsey \& Company, 2017). These factors have spawned an increased demand across the creative economies for graduates who demonstrate divergent thinking and possess skills in idea generation (Bill, 2012; Im, Hokanson, \& Johnson, 2015; Karpova, Marcketti, \& Barker, 2011). Fashion educators then must scrutinize their current practices to ensure that their methods and curriculums are effectively grooming current and future students for the rapidly evolved landscape in which they will work.

Researchers have shown that assessment design influences student conduct, and that it is an essential element for student learning and engagement (Bennett, Dawson, Bearman, Molloy, \& Boud, 2017; Dunphy, Mullane, \& Allen, 2016; Evans, 2013). Freeman, Son, and McRoberts's (2015) research on creativity assessment within fashion illustration evaluations found that "the major factor limiting further creativity development in fashion programs continues to be a lack of effective evaluation and/or evaluation tools for faculty" (p. 122). Many scholars agree that there is a need to improve evaluation techniques generally in higher education (HE; Atkinson \& Lim, 2013; Franklin \& Smith, 2015; Freeman et al., 2015) and yet curiously, most studies on the use of technological tools to aid assessment have focused primarily on primary and secondary school use rather than its applications within HE (Chen, Lao, \& Sheum 2003, Rogers et al. 2005, Sharples, Corlett, \& Westmancott 2002, as cited in Franklin \& Smith, 2015; Nikou \& 
Economides, 2018). Notably, Mobile-Based Assessment (MBA) is an emergent research field within the broader mobile learning area, despite a gap in literature (Nikou \& Economides, 2018).

\section{Research Aims for This Study}

The impetus for this Major Research Project (MRP) came from the researcher's own experiences with providing feedback and assessment as an educator in $\mathrm{HE}$ in the field of fashion design. Hypothesizing that the collective community of practice and the diverse student groups studying today may benefit from contemporized pedagogical methods that are better aligned with current societal, technological, and industry developments, the researcher was compelled to direct change by materializing solutions to the obstacles she and her colleagues faced in their everyday work.

The study first looks at the practices currently used to evaluate and provide feedback to students on creative projects within fashion design programs in HE, in order to set a baseline for the praxis. It identifies areas for reform and improvement, followed by creative exploration in the development of a technological solution: a faculty-facing mobile assessment and feedback app for assessing and providing students feedback on their creative projects. The proposed technological solution, in keeping within the scope of this MRP, was developed to a prototype stage only.

The expected areas for improvement are: providing accessibility for diverse learners; considering the unique needs of Millennial learners; difficulties in providing clarity and specificity in feedback due to time constraints in live critiques; timeliness of providing written feedback; accuracy of information; and workload burdens on faculty in regards to record keeping. Perhaps most importantly, the current social, economic, and fashion industry demands will be addressed to refocus the assessment of design works to encompass a greater emphasis on divergent thinking supported by formative assessment. 


\section{CHAPTER 2: LITERATURE REVIEW}

The literature review focused on several areas that together would inform the building of an innovative and effective technological assessment tool that will address the issues faced by faculty and students in current praxis. The researcher has identified two gaps in scholarly research: (a) the use and need of Mobile-Based Assessment (MBA) in HE specifically and (b) assessment methods utilized within the domain of fashion design. This study aims to contribute to these gaps in research. The review surfaced several key themes that are summarized below.

\section{Slow Adoption for the Use of Technology in Assessment Design in HE and the Emerging Research Area of MBA}

Most research into the use of technology in education is geared towards mobile learning rather than mobile assessment, and the literature that was specific to assessment pertained mostly to its use in primary or secondary school education (Nikou \& Economides, 2018). This gap in research has opened the door for an emerging research area-MBA (Nikou \& Economides, 2018) - for which the researcher hopes to contribute to with the proposed technological solution. However, some key themes relating to assessment in $\mathrm{HE}$ was gleaned from the literature.

First, there are slow adoption rates for technology use in assessment design within HE (Bennett et al., 2017; Dunphy et al., 2016; Franklin \& Smith, 2015). There are known advantages to using technology in assessment, which include streamlining the assessment process, improving timeliness of students receiving feedback, saving instructor time, saving paper, enhancing experiential learning, and its ability to provide robust accessible feedback outputs such as audio, visual, or video feedback (Franklin \& Smith, 2015; Nikou \& Economides, 2018; Spector et al., 2016). Despite the many benefits, faculty in HE are slow to adopt technology, seemingly for reasons such as (a) lack of time to explore new methods, (b) shortage of financial resources to implement new technologies (Bennett et al., 2017), or (c) the comfort of using 
unstandardized or informal assessment techniques that have been used in the past (Atkinson \& Lim, 2013). Second, creative development within fashion HE programs is thought to be underserved due to the inadequacy of evaluation methods and/or absence of effective technological evaluation tools for faculty use (Freeman et al., 2015).

\section{Assessing Creativity Using the Creative Assessment Technique}

In 1982, Teresa Amabile developed a framework for assessing creativity: the Creative Assessment Technique - known as CAT. This technique is a highly regarded tool in assessing creativity across many creative industry fields (Kaufman, Baer, Cole, \& Sexton, 2008). Many studies involving the CAT technique have been reviewed. The findings indicate that creativity as an attribute can be distinguished separately from other attributes of design work such as technical aspects (Jeffries, Zamenopoulos, \& Green, 2018), which is important to understand when designing the app assessment features or rubric criterion for app templates. Also important in the findings of CAT reviews is that experienced domain experts will most often assess creativity similarly based on their own individual notions of creativity, without being given criterion for creativity itself (Baer \& McKool, 2009).

\section{The Importance of Feedback in the HE Learning Process}

Carol Evans in 2013 performed a widespread thematic review of scholarly literature containing topics in the area of feedback in HE. She then utilized the core themes that emerged to inform the development of a twelve-point framework she calls the "The Principles of Effective Feedback" (Evans, 2013, p. 80). Highlighted in her analysis was that $76 \%$ of the articles reviewed included discussions regarding feedback interventions slated to strengthen learning, and that providing feedback is an essential part of evaluation. Also notable was a 2016 study by Spector et al. that stressed the importance of feedback in formative assessment for 21 st century 
learning specifically, and who also suggested that providing timelier and more effective feedback can likely only be achieved through the faculty use of new technological tools.

\section{Large Differences in Millennial Learners and the Need for Universal Instructional Design in Assessment Design}

The researcher found throughout the reviewed literature that there are many differences in how Millennials - those students who are currently aged 15-36 (Raphelson, 2014) and who now occupy the majority of university programs in North America (DeBard, 2004)—learn. These studies articulate very specific and differing needs and traits of today's learners, which include: having less patience; using technology to express themselves; preferring digital and aesthetically pleasing teaching materials; requiring extra support in their learning process; possessing an openness to receiving feedback; commonly multi-tasking while learning; and having a need to access documents and further resources outside of traditional school hours (Lippincott, 2010; Roberts, Newman, \& Schwartzstein, 2012). The researcher questions whether these needs are being met in current assessment and feedback practices.

There is also a growing diversity among the student population (Malcolm \& Roll, 2017; Radclyffe-Thomas, 2015; Samuels-Peretz \& Powers, 2014). This diversity calls for assessment to be more flexible and tailored to the student's specific needs. The need for personalization within assessment and "blended instructional modalities" (Bocconi \& Trentin, 2014, p. 516) can be supported by Universal Instructional Design (UID) pedagogies, which strive to make education accessible for all students (Samuels-Peretz \& Powers, 2014).

Accessibility can be considered when designing assessment and feedback documents. Technological advancements have allowed us to think differently about how feedback can be given to accommodate the needs of diverse learners. Feedback, for example, could be furnished via pictures, audio, or video, and not just in written form. Plug-ins that provide language 
translation or diction that can accommodate students new to a language, or those who may have visual impairment, can be added to digital assessment documents. Embedded links to connect the student to additional learning or reference resources could be offered within the digital document as well.

\section{State of the Fashion Design Industry: Demand for Divergent Thinking}

Many industry-specific articles have been reviewed that similarly point out that "creativity has been deemed to be of utmost importance for the success of future fashion designers in an ever more competitive industry environment with flattened employment demand" (Karpova, as cited in Freeman et al., 2015, p. 122). Fashion scholars such as Amanda Bill (2012) have emphasized the notion that creativity and divergent thinking — "the process of generating multiple ideas to maximize the range of possible solutions" (The University of Texas at Austin, Faculty Innovation Center, 2019, p. 1) — are key success factors for design graduates.

The fashion system, which is in a state of drastic transformation due to geopolitical, environmental, technological, and social pressures, is seeing even well-established corporations emulating start-up mentalities in order to escalate innovation (The Business of Fashion and McKinsey \& Company, 2017). Globalization and automation impact traditional roles, and the demand for new employees who can think divergently is key.

The U.K. has identified creativity as a core skill for the nation's success in the postindustrial economy (Radclyffe-Thomas, 2015), while the U.S.-based Partnership for 21st Century Learning $(\mathrm{P} 21,2019)$ includes critical thinking in its framework of essential 21st century skills for students to succeed in employment and life. 


\section{CHAPTER 3: CONTEXTUAL REVIEW \\ Competitive Products in the Marketplace}

This action research was spurred in part by the researcher's personal view that there is a lack of availability of effective mobile assessment tools that include her desired functionality. The researcher conducted a further marketplace scan via Google searches and visiting app stores for assessment apps suitable for evaluating creative projects in HE. Though many apps and webbased solutions involve assessment tools, the researcher found that the majority were focused on primary and secondary school applications, a finding that coincides with Nikou and Economides's (2018) findings.

The following popular apps were informally reviewed by the researcher: FreshGrade, ForAllRubrics, Kaizena, Sesame, and Seesaw. Though aspects of the functionality in many of these products were applicable to the proposed app development, it was evident that the focus of these products was on informal formative assessment techniques and information and portfolio sharing with the parents of school-grade children. The overall features, functionality, and design of the products, coupled with their lack of integration with HE learning management systems (LMSs), prohibits their general adoption in fashion design assessment within postsecondary settings.

\section{Learning Management System Assessment Tools}

Most LMSs designed for HE incorporate built-in assessment tools and rubrics. These rubrics are valuable in that they save time due to the semi-automation of some tasks (Atkinson $\&$ Lim, 2013), provide organized stored records for the department, and offer 24/7 access to students. The researcher's limited review has found that they do not offer the flexibility, degree of customization, or the range of feedback formats that may be necessary for wider use within creative project assessment. 
Some researchers have explained that the lack in use of technology in assessment design was due primarily to the lack of training and support for faculty who wish to learn and design assessment with the use of technology (Atkinson \& Lim, 2013; Bennett et al., 2017), and secondly due to the "limitations to the tools themselves" (Bennett et al., 2017, p. 678). 


\section{CHAPTER 4: METHODOLOGY}

\section{Research Design: Practice-Based Participatory Action Research Utilizing Design Thinking Approach}

This study employs practice-based participatory action research, utilizing a design thinking approach. Participatory action research is a form of research that is spawned due to a need for an improvement to a process or practice (Kemmis, 2009). The research design was a natural choice since the researcher was dissatisfied with aspects of the feedback and evaluation methods used within her own practice, and hypothesized that the issues she faced may well be widespread in her field. The researcher wished to act on finding a solution that could potentially benefit the community of practice, which is the premise of action research.

Design thinking concerns itself with the human experience of interacting with technology (Braun, 2016; Gobble, 2014) via cycles of iterative design development followed by userfeedback and testing sessions, more refinements, and more testing, until results are deemed acceptable to the users/designer (Razzouk \& Shute, 2012). This approach is a widely accepted method for developing user-based technological products (Seidel \& Fixson, 2013) and allowed the designer to make continual improvements to the outcome of the prototype as part of her creative solution-seeking exploration.

\section{Theoretical Approach}

This practice-based study leans on applied theories through praxis. Methods for critiquing design work utilized in academic environments were considered and applied. Teresa Amabile's framework for assessing creativity - the Consensual Assessment Technique (CAT) proposed in 1982 (Baer \& McKool, 2009)—underpinned the templates for rubric criterion. Ideas drawn from Universal Instructional Design (UID) pedagogies that aim to promote accessibility within teaching and feedback documents to better serve today's diverse learners (Samuels-Peretz \& 
Powers, 2014) are integral to the study. Socio-constructivist feedback pedagogies, defined as those that are less directive but rather facilitate students in their ability to make revisions to their projects themselves (Archer, 2010; Evans, 2013), also influenced the overall design and functionality of the prototype.

The research design intended to: (a) determine the current standard of praxis amongst instructors, primarily those working in fashion design, but also in the related domain of interior design, who provide student feedback and assessment on creative projects within HE settings; and (b) understand the challenges and barriers these instructors and students may face with their current methods. These data were analyzed considering the frameworks and theoretical approaches outlined above, prior to moving to the third and final creative process phase of the study where the prototype of the app was developed. 


\section{CHAPTER 5: METHODS}

\section{In-Depth Qualitative Interviews}

In-depth interviews were conducted with two separate groups: (a) faculty who assess creative projects in fashion design HE programs and, in one case, the related domain of interior design; and (b) recently graduated fashion design students from Ryerson University's Apparel Design program. Both sets of in-depth qualitative interviews were designed similarly; they were an hour in length and were audio recorded, later transcribed, and subjected to thematic analysis. Questions were mostly open-ended with opportunities for spontaneous questioning and free conversation between the interviewer and interviewee.

\section{In-Depth Faculty Interviews}

The goal of these interviews was to establish a baseline for the current standard of praxis in the feedback and assessment of creative projects within HE fashion design and related domain programs, and to understand the issues and barriers facing faculty in those practices.

Recruitment was purposive in nature, as it was important to target faculty from a very specific group of instructors. Personal contacts, and those of colleagues, were utilized to recruit these participants. Faculty participants were required to have at least 3 or more years of teaching experience in HE, and an emphasis was placed on recruiting professionals who would represent separate, highly regarded design schools in Europe, Asia, and North America. Five participants were recruited. One of the five was from the researcher's own department in Ryerson University's undergraduate program in Fashion Design, as the researcher was more familiar with the processes used within her own department, but wanted to ensure that data were collected from faculty members representing various esteemed fashion institutes.

The line of questioning for the faculty participants was geared towards learning about their current methods in providing student assessment and feedback, the use of technology within 
their practice, barriers they may face with their work, desires for improvements in their methods, and experiences with the specific needs of current student learners.

\section{In-Depth Past-Student Interviews}

The second participant group included two recently graduated fashion design students from Ryerson University's undergraduate program in Fashion. Here, the researcher wanted to gain the perspective of the students' experience with receiving assessment and feedback in their

studies, and to ascertain the areas of their experience where they believe improvements could be made. To mitigate any potential conflict of interest, past-student participants selected had not been taught by the researcher in their upper-level fashion studies.

\section{Thematic Analysis of In-Depth Interview Data}

The researcher audio-recorded all interviews. The in-depth interview recordings were then submitted to the online transcription service Trint.com for transcription. The preliminary transcribed files required further editing by the researcher, as there were some transcription errors. The final transcribed files were then reviewed several times by the researcher, which helped her to identify common themes. Once common themes were identified, the files were coded with colours that corresponded to each theme. Further analysis of the coded data allowed the researcher to establish a baseline of praxis, and to define areas of focus for feature inclusions and general functionality of the app.

\section{Define App Architecture Using Design Thinking Approach}

Utilizing a design thinking approach whereby the usability of the product is developed through an iterative process of design, feedback, refinements and user-testing cycles (Razzouk \& Shute, 2012), the researcher first set out to plan the architecture of the mobile app by listing the desired features and functions that the app would include. These features and functions were established through the consideration of the interview data results and supported by the literature 
review on contemporary pedagogies in feedback and assessment, frameworks of Universal Instructional Design, assessing creativity, and research on the specific needs of today's diverse learners. This Excel breakdown allowed for an initial conceptualization of the flow of steps each feature would require. Separate Excel tabs were used to elaborate on each screen or tool. The main app architecture Excel schematic is included in Appendix A, and an example of detailed function breakdown schematic is included in Appendix B.

\section{Qualitative Interviews: User-Feedback Sessions}

In this stage the researcher presented the Excel layout of the proposed app features to three user-testing participants: two faculty members recruited from the in-depth interview participant group, and a UX professional. After presenting the preliminary architecture and features, the researcher conducted qualitative informal unstructured interviews with the participants to gain initial feedback at this early stage of development. All sessions were audio recorded, but not transcribed, and notes were taken. These data was reviewed and considered in the next steps of the development.

\section{Design Thinking Iterative Process: App Development}

During this in-depth creative phase of development, the researcher worked with the UX professional to structure initial wireframes within app prototyping software Adobe XD. The focus here was information architecture rather than aesthetics, ensuring that all required steps within the app were sequenced according to good principles of usability. The researcher and UX professional worked back and forth within Adobe XD, discussing intentions and refining the flow in order to achieve the technological solution envisioned by the researcher. Through this iterative process the researcher discovered and implemented additional ideas, eliminated redundancies, and realized unanticipated app requirements. For example, this process revealed the importance of security and privacy required when handling students' grades and evaluation. 
From here, aesthetic decisions such as the layout of the app screens and the appearance of icons, fonts, and colours were refined. A screenshot representing a visual of early design stages within Adobe XD is included in Appendix C.

\section{Preliminary User-Testing Session}

Once the prototype reached an initial functional stage, a preliminary user-testing session was conducted with the same three participants. These preliminary user-testing sessions comprised online testing of the prototype within the Adobe XD sharing function. The researcher then performed informal unstructured qualitative exit interviews regarding the user's experience interacting with the prototype. The goal of this preliminary testing was to identify any significant exclusions, or any difficulties with flow or comprehension of steps or functions. The interview data were analyzed informally to inform the next steps in the iterative design and refinement process, and to point the researcher to any additional research that may be necessary.

\section{Finalize Design of App Prototype}

These results, along with further consultation with the UX professional, led to final revisions to the app design. It is acknowledged that this research project concludes with what is, essentially, still a design-prototype. Before this product would be ready for further development and product realization, the prototype in its current state should be subjected to additional rigorous user-testing sessions and further iterative feature-design that are beyond the scope of this MRP project. 


\section{CHAPTER 6: ANALYSIS AND DISCUSSION \\ Qualitative Interview Findings}

\section{Faculty Interviews}

These interviews were focused on learning the processes currently being applied in evaluation and feedback praxis at well-known fashion and interior design degree-granting programs in North America, Europe, and Asia, and to learn of the issues and barriers that faculty and students face with current methods. The analysis of the data from the faculty interviews surfaced the following common themes.

Lack of time to perform work as thoroughly and as adequately as desired. The data indicated that the biggest barrier facing instructors in their practice was lack of time. All instructors interviewed referred to time-constraints as a large contributor in their ability to perform effectively, and made many comments concerning the shortage of time, such as: "I just don't have time to type it out" (Faculty Participant B, personal communication, January 3, 2019); "It would be beneficial if I could get it to them sooner" (Faculty Participant D, personal communication, October 16, 2018); and "We just don't have the time" (Faculty Participant A, personal communication, October 16, 2018). One participant described scheduling student critiques on weekends as there was not enough time to complete assessment during the class time or week days (Faculty Participant D, personal communication, October 16, 2018).

Faculty spend a great deal of time documenting repetitive comments to many students. Faculty agreed that they tend to "write the same thing over and over" (Faculty Participant B, personal communication, January 3, 2019), and were all excited by the notion that this proposed solution would have pre-programmed and/or self-populating comments that could be scrolled and chosen in less than a second. Participant $\mathrm{E}$ was very responsive to the idea of scrolling down to pick a repetitive comment: “...just touching it—-that would be great” (Faculty Participant E, Personal Communication, October 19, 2018). 


\section{Faculty are concerned that current cohorts of learners lack information retention,}

and often do not take notes. All interviewees felt that their students rarely take notes, and some noted that if they did, it was on their phones. Some expressed concern about the lack of information retained and were troubled at how current cohorts approach learning (Faculty Participant A, personal communication, October 16, 2018; Faculty Participant B, personal communication, January 3, 2019). When asked if they felt that providing feedback digitally, in a timelier manner via a variety of mediums, would help retention, they harmoniously agreed that it would.

Most faculty like to review live critique assessments and rubrics afterwards, adding and editing comments and marks before finalizing document for student view. Many faculty members spoke of returning to the rubrics after the live critiques to formalize their comments, adding additional information, and double checking their assessments, or because they are aware that they are "very candid with their original thoughts" (Faculty Participant E, October 19, 2018) and need to adjust the verbiage before submitting to students. Faculty Participant A noted that "I like to reflect a bit" (Personal communication, October 16, 2018), while another noted that it is easy to "overlook or forget certain things" (Faculty Participant D, personal communication, October 16, 2018). Participant A explained that "because it is such a short amount of time, sometimes my writing is chicken scratch so I have to go back in and analyze what I wrote" (Personal communication, October 16, 2018) as a reason for needing to return to the rubric at a later time.

\section{Desire to have visual and photographic reference of live critiques, but concerned} they cannot manage the logistics of this process in short critiques. When asked if they thought that having photographic reference of the live critique embedded in the rubric would be helpful, all participants said yes. Most commented on the fact that the visual feedback could 
greatly improve communication particularly if they could write on top of the image, but also that it would support the "need to document for the protection of the school" (Faculty Participant C, personal communication, November 20,2018) and that it is important that "they have a copy, and we have the same copy" (Faculty Participant A, personal communication, October 16, 2018), rather than physically returning the only copy to the student as a point of documenting.

Students are always on their phones and are digitally inclined. Many of the participants added that they perceive students "are so tech-savvy" (Faculty Participant A, personal communication, October 16, 2018) and are "always on their phones" (Faculty Participant B, personal communication, January 3, 2019). This point ties in to the literature review findings that suggest today's learners are digitally inclined and interested in interactive digital mediums (Lippincott, 2010). This highlights the need for a digital and interactive evaluation output that is proposed in this study.

Lack of written feedback or breakdown of grading attributes. One participant commented that many of the internal faculty within his/her department still practise evaluation with a single letter grade and simply suggest that the student visit office hours if they needed to have additional feedback (Faculty Participant B, personal communication, January 3, 2019). While another confirmed that they knew of colleagues who give very little feedback (Faculty Participant C, personal communication, November 20, 2018). Both participants surmised that this was likely due to time constraints and/or discomfort with learning new technology, but also noted that they felt this practice was not conducive to effective pedagogical practice (Faculty Participant B, personal communication, January 3, 2019).

\section{Welcome technological solution to perform assessment and feedback functions.}

Faculty Participant A welcomes voice recording for his/her own purpose, believing that he/she can go back and understand what he/she was thinking at the time in order to formalize 
comments: "absolutely, I would like to use technology if I can" (Personal communication,

November 20,2018). One interviewee described that his/her process of making comments on the sheet with a pen was "arduous because I have terrible writing" (Faculty Participant A, personal communication, October 16, 2018). All interviewees expressed enthusiasm about the idea of using a tablet for the purpose of assessment and feedback documentation within the classroom.

\section{Many do not utilize rubrics in information management systems due to either their} lack of comfort and training with the systems, and/or due the inflexibility of their use. Two out of the five participants stated that they do sometimes use rubrics within information management systems (IMSs), however both noted that there were limitations to their use - that is, ability to access a computer during a live critique, or to edit or change criterion or page layout to instructors' desire (Faculty Participants A \& D, personal communication, October 16, 2018). Other participants have never tried to use these systems. One stated that he/she is "currently upgrading himself/herself to use online rubrics" (Faculty Participant E, personal communication, October 19, 2018). Participant B cited that many of his/her colleagues were in their 60s and 70s and many of them were resistant to learning new technology, and therefore still reverted to traditional hand-written letter-grade assessments (Faculty Participant B, personal communication, January 3, 2019).

Language barriers. Some participants discussed that there can be difficulties communicating the feedback to some students. One participant who taught in Asia explained that most of the fashion instructors were brought in from foreign countries and do not speak the country's primary language, and thus may also be less aware of cultural differences and perceptions (Faculty Participant D, personal communication, October 16, 2018), while another participant remarked that she felt sometimes she is unaware that a student did not understand her 
comments until much later when it becomes apparent (Faculty Participant E, personal communication, October 19, 2018).

\section{Increase in student stress anxiety and learning disabilities affects practice.}

"Everyone just seems to be so stressed" (Faculty Participant C, personal communication, November 20, 2018) was the sentiment amongst most interviewees. Increases to the number of students requiring accommodation for learning disabilities or other health issues, and/or those who are missing classes due to mental health reasons, is perceived to be on the rise. Interviewees overwhelmingly agreed that supplying feedback digitally in a timelier manner, in a variety of formats (audio, photographic, links to external reference materials), would greatly improve the quality of instruction for these learners.

\section{Need for individualizing feedback and evaluation based on students' unique}

approaches to assignments. Participant $\mathrm{C}$, who teaches in a prestigious school in Europe, noted that his/her department is currently aiming to be more flexible and holistic with the approach taken in guiding final capstone projects, one that allows individual preferences to be considered in assignment outcomes (Personal communication, November 20, 2018). Participant A noted that the standard rubric criteria do not always match the students' specific assignment approaches (Faculty Participant A, personal communication, October 16, 2018). If there is a trend to offer more flexibility and individualization to the students' educational journey, then instructors will need to think about ways they can fairly customize rubrics to suit all project approaches.

\section{Student Interviews}

These interviews involved two recent graduates from Ryerson's fashion program, one of whom also spoke of her experiences studying in a graduate program in Europe as well. The questions focused on the students' perspective as to how they were evaluated and given feedback in their upper-level studies in their undergraduate program or in their graduate studies, and asked 
where they felt there was opportunity for improvement. The key themes coming out of those interviews are described below.

There is a desire for more flexibility in assessment and feedback that is individualized and focused on creative aspects. Both interviewees felt creativity and creative process were not valued, and in some cases not even graded, but rather that rubrics were disproportionately focused on technical aspects of the artifact (Student Participant A, personal communication, November 9, 2018; Student Participant B, personal communication, November 6, 2018). Student Participant B expressed the notion that he/she would like to have had feedback on areas of his/her project process work that were not a part of the rubric, but was unable to receive such feedback (Personal communication, November 6, 2018). Student Participant A expressed the need for "more flexibility in rubrics" which he/she felt would also help to improve student-instructor relationships (Personal communication, November 9, 2018).

Evaluation focused heavily on end results, and not enough ability to receive individualized feedback on process work. Both interviewees focused on this concern and believed there should be more of a focus on formative feedback.

\section{Want more creative freedom within their projects and therefore do not want} assessment to penalize them for taking a different approach. Both participants described situations where they felt the structure or evaluation penalized them for stepping outside the boundaries laid out for them in their journey to project completion, and felt that this was unjust. The students both expressed the desire to be evaluated more holistically on their efforts and creative process based on their individual strengths, weaknesses, and project goals, and less about "rule-following" (Student Participant A, personal communication, November 9, 2018) by their instructors. 


\section{Embrace audio recording to better digest information by re-listening to critique}

comments at later points in time. Student Participant B described that in his/her graduate

studies in Europe, all critiques are audio recorded, and he/she emphasized how helpful it is to be able to re-listen to the critique afterwards, and that a deeper understanding of the feedback was achieved through this process (Personal communication November 6, 2018).

\section{Embrace the use of photos and videos within rubric to further clarify feedback}

given. When asked if they thought that the inclusion of notated photos or videos of their critique feedback documents would be helpful, both felt that it would definitely would, especially since "we are all visual people" (Student Participant A, personal communication, November 9, 2018). It was also noted that some students were irritated when their original work was "marked up" (Student Participant A, personal communication, November 9, 2018) by their instructors, and welcomed the use of notated digital images that would eliminate this practice.

\section{Embrace interactive digital documents that can be accessed from anywhere at any}

time. Both participants agreed that it would be beneficial to have their assessments available in the cloud, and liked the idea that they could be accessible at any time and from any place, and that the process would eliminate the wait to have a physical copy returned at a later class time.

\section{Lack of time to seek out instructors for additional feedback outside of class time due}

to heavy class workloads and part-time jobs. Student Participant A explained that though he/she would like to have sought out more advice from his/her instructors during office hours, it was difficult to make it to office hour times as they were not always aligned with their class schedules, part-time job schedules, or simply didn't have the time due to overwhelming workload (Personal communication, November 9, 2018).

Self-directed learning is necessary since projects are often very individual. Both participants described the need for students to pursue learning on their own that was specific to 
their projects due to the varied approaches and categories of garment making that students were pursuing.

\section{Summary of Interview Findings}

It is apparent from the data analysis from both interview groups that more flexibility is needed in the way feedback and evaluation is given for increased effectiveness. It is also very apparent that the timeliness and accessibility of the feedback is of utmost importance. With all faculty participants expressing time constraints impeded on their ability to perform their tasks in an ideal way and students expressing the need for more formative and accessible feedback, it is understood that the app solution must aim to save the user time, while providing robust and varied digital mediums to deliver the feedback that is most suitable to diverse learners and to the nature of the critique.

\section{Features Inclusion}

\section{Features Directive}

The features included in the app were established through the careful consideration of the literature review, the analysis of qualitative interviews, and the feedback received in user-testing feedback sessions. The chosen features aim to satisfy the following criteria:

1. Save time for faculty members responsible for providing feedback and assessment via shortcuts, automated tasks, and the elimination of duplicated steps such as re-typing what you have handwritten, or copying and pasting information into a separate document or format.

2. Improve on the accessibility of the feedback considering the frameworks put forth in UID Pedagogies (Samuels-Peretz \& Powers, 2014) and considering the varying needs of the increasingly diverse student body.

3. Improve on the timeliness of the feedback cycle, supporting the need for more formative 
assessment (Spector et al., 2016).

4. Improve on accuracy and organization of record keeping.

5. Improve the effectiveness of feedback by providing specific and personalized feedback made easier through a wider range of mediums, such as photos, videos, or audio, or interactive links to further learning and reference materials that can be explored. The researcher has noted that verbiage used in pre-designed template criteria must be flexible as to capture variances in projects, and will consider this in designing rubric templates for use within the app.

6. Improve student engagement by providing timely, more relevant, and additional information via a digital format, that they can access at any time, from anywhere, that can aid self-directed learning.

7. Promote divergent thinking through the ease at which faculty can supply student with timely, individualized formative feedback, in an engaging medium that can capture the nuances of creative projects and aim student to further design research.

\section{Features List}

Table 1 presents the list of established features included in the app design. 
Table 1

App Features List With Description and Value Offering

\begin{tabular}{|c|c|c|}
\hline Feature name & Description & Value offering \\
\hline Dashboard timer & $\begin{array}{l}\text { Timer on rubric screen to help assessor } \\
\text { stay on schedule with critique time. }\end{array}$ & $\begin{array}{l}\text { Ease of use, saving time, no } \\
\text { need to access anything outside } \\
\text { of app, or reach for another } \\
\text { device. }\end{array}$ \\
\hline Draw/scribble & $\begin{array}{l}\text { Ability to draw on top of photos, hand } \\
\text { write rather than type, draw, circle, } \\
\text { highlight, etc. Drawing function } \\
\text { utilizes tablet pen technology and } \\
\text { offers different line weights and } \\
\text { colours, eraser and straight-line ability. }\end{array}$ & $\begin{array}{l}\text { Some users find writing faster } \\
\text { than typing, ability to better } \\
\text { articulate point by drawing } \\
\text { pointed notes to a photo, } \\
\text { inserted object, etc. }\end{array}$ \\
\hline Free type & Add editable type anywhere on a page. & $\begin{array}{l}\text { Add type where you want it, } \\
\text { even on top of a photo. }\end{array}$ \\
\hline Type in a box & Have type appear in a bordered box. & $\begin{array}{l}\text { Ability to formalize page layout } \\
\text { through type boxes. }\end{array}$ \\
\hline Add a photo & $\begin{array}{l}\text { Utilizes tablet photo technology, } \\
\text { quickly adds photo within the rubric } \\
\text { page, with size and crop editing } \\
\text { functionality. }\end{array}$ & $\begin{array}{l}\text { Ability to have a more accurate } \\
\text { record of what was being } \\
\text { assessed in live critique, ability } \\
\text { to go back and review, add } \\
\text { further comments later, ability to } \\
\text { clarify comments by drawing or } \\
\text { writing on top of photo, } \\
\text { highlighting or circling to } \\
\text { reference certain areas of object. } \\
\text { Eliminates the need to damage } \\
\text { physical assignment by adding } \\
\text { comments, pen marks on the } \\
\text { artifact directly. }\end{array}$ \\
\hline Add a video & $\begin{array}{l}\text { Utilizes tablet video technology, } \\
\text { quickly adds video within the rubric } \\
\text { page, with editing functionality. }\end{array}$ & $\begin{array}{l}\text { Ability to have a more accurate } \\
\text { record of what was being } \\
\text { assessed in live critique, ability } \\
\text { to go back and review add } \\
\text { further comments later, ability to } \\
\text { clarify comments by drawing } \\
\text { writing on top of photo, } \\
\text { highlighting or circling to } \\
\text { reference certain areas of object. }\end{array}$ \\
\hline
\end{tabular}


Table 1 (cont'd)

App Features List With Description and Value Offering

\begin{tabular}{|c|c|c|}
\hline Feature name & Description & Value offering \\
\hline $\begin{array}{l}\text { Add an audio } \\
\text { recording }\end{array}$ & $\begin{array}{l}\text { Utilizes tablet audio technology, } \\
\text { quickly adds audio clip within the } \\
\text { rubric page, with editing functionality }\end{array}$ & $\begin{array}{l}\text { Ability to have a more accurate } \\
\text { record of what was being } \\
\text { assessed in live critique, ability } \\
\text { to go back and review add } \\
\text { further comments later, allows } \\
\text { student to review what was said } \\
\text { without having to take notes in } \\
\text { the live setting, allowing his/her } \\
\text { focus to be on the instructor who } \\
\text { is speaking. Provides } \\
\text { accessibility to visually } \\
\text { impaired, or those who may } \\
\text { have difficulty reading the } \\
\text { language used. }\end{array}$ \\
\hline $\begin{array}{l}\text { Add type, } \\
\text { handwriting on top } \\
\text { of photos }\end{array}$ & $\begin{array}{l}\text { Write with pen anywhere on the page, } \\
\text { including over top of photos. }\end{array}$ & $\begin{array}{l}\text { Clarify points by pointing, } \\
\text { circling, highlighting areas that } \\
\text { comments are referencing. } \\
\text { Provides accessibility to those } \\
\text { that may be experiencing } \\
\text { language barriers or cultural } \\
\text { differences, as photos can } \\
\text { quickly tell a story that } \\
\text { sometimes words cannot. }\end{array}$ \\
\hline $\begin{array}{l}\text { Open a pdf within } \\
\text { doc }\end{array}$ & $\begin{array}{l}\text { Bring in existing marking sheets or } \\
\text { documents that you would like to write } \\
\text { or type over top. }\end{array}$ & $\begin{array}{l}\text { Flexibility with method to be } \\
\text { used, time saving. }\end{array}$ \\
\hline Use a pre-set rubric & $\begin{array}{l}\text { Open up pre-designed rubrics that are } \\
\text { editable. }\end{array}$ & $\begin{array}{l}\text { Save time from setting up from } \\
\text { scratch. }\end{array}$ \\
\hline $\begin{array}{l}\text { Set up a rubric } \\
\text { criteria box }\end{array}$ & $\begin{array}{l}\text { Set up your own rubric criteria box } \\
\text { with grade points. }\end{array}$ & $\begin{array}{l}\text { Flexibility and control for rubric } \\
\text { design. }\end{array}$ \\
\hline $\begin{array}{l}\text { Easy Slide Grade } \\
\text { picker }\end{array}$ & Slider picker to choose grade & $\begin{array}{l}\text { Fast to use and accurate, easy to } \\
\text { see how chosen grade affects } \\
\text { total, fast to edit and change } \\
\text { without erasing. }\end{array}$ \\
\hline
\end{tabular}


Table 1 (cont'd)

App Features List With Description and Value Offering

\begin{tabular}{|c|c|c|}
\hline Feature name & Description & Value offering \\
\hline $\begin{array}{l}\text { Automated grade } \\
\text { totalling and grade } \\
\text { equivalents }\end{array}$ & $\begin{array}{l}\text { Summation capability, all criteria } \\
\text { boxes will add together and display a } \\
\text { total, configured how you want it to. }\end{array}$ & $\begin{array}{l}\text { Saves time as no need to add; } \\
\text { eliminates grade adding errors. }\end{array}$ \\
\hline $\begin{array}{l}\text { Automated upload } \\
\text { batch or item to D2L }\end{array}$ & $\begin{array}{l}\text { When marking complete ability to } \\
\text { batch upload all rubrics to the } \\
\text { associated student within D2L shell, } \\
\text { including attaching the pdf rubric, and } \\
\text { inputting the grade to the grade area. }\end{array}$ & $\begin{array}{l}\text { Save time attaching individually, } \\
\text { allows for more timely access by } \\
\text { students, provides } \\
\text { confidentiality and security in } \\
\text { process of providing feedback } \\
\text { and evaluation. }\end{array}$ \\
\hline $\begin{array}{l}\text { Self-populating } \\
\text { rubrics with student } \\
\text { names }\end{array}$ & $\begin{array}{l}\text { Rubric will have name populated from } \\
\text { D2L class list. }\end{array}$ & $\begin{array}{l}\text { Saves time, and provides } \\
\text { accuracy and professionalism, } \\
\text { eliminating spelling errors, and } \\
\text { mixing name errors. }\end{array}$ \\
\hline $\begin{array}{l}\text { PDF outputs ready to } \\
\text { auto upload to LMS, } \\
\text { print, or email }\end{array}$ & Rubric is already in PDF format. & $\begin{array}{l}\text { Saves time and is easily } \\
\text { viewable in many different } \\
\text { computers and programs, can be } \\
\text { sent through email, student } \\
\text { cannot edit. Provides more } \\
\text { thorough formative feedback to } \\
\text { student. }\end{array}$ \\
\hline $\begin{array}{l}\text { Auto populate } \\
\text { repetitive comments }\end{array}$ & $\begin{array}{l}\text { Once you type a comment with one } \\
\text { click you can add it to your repetitive } \\
\text { comment library. }\end{array}$ & $\begin{array}{l}\text { Save time having to add or recall } \\
\text { comments for library, add them } \\
\text { while using app. }\end{array}$ \\
\hline $\begin{array}{l}\text { Repetitive comment } \\
\text { scrolling picker }\end{array}$ & $\begin{array}{l}\text { Choose repetitive comment from fast } \\
\text { scroll list. }\end{array}$ & $\begin{array}{l}\text { Quickly add phrases without } \\
\text { retyping, editable. }\end{array}$ \\
\hline Add a link & Places a URL link into page. & $\begin{array}{l}\text { Provides interactive link to } \\
\text { digital document to easily } \\
\text { connect students to further } \\
\text { documentation, references, } \\
\text { instructional materials, etc. } \\
\text { Provides accessibility to those } \\
\text { with learning impairment as they } \\
\text { can be directed to additional } \\
\text { learning materials or references } \\
\text { to enable learning. }\end{array}$ \\
\hline
\end{tabular}


Table 1 (cont'd)

App Features List With Description and Value Offering

\begin{tabular}{lll}
\hline Feature name & Description & Value offering \\
\hline Add a logo & $\begin{array}{l}\text { Place a logo or any graphic object } \\
\text { saved to app, photos, or Google or } \\
\text { Onedrive, on to page. }\end{array}$ & $\begin{array}{l}\text { Size editable, allows for } \\
\text { professional rubric display. }\end{array}$ \\
Undo & Undo last several actions. & Quickly undo mistakes. \\
$\begin{array}{l}\text { Embed Translation } \\
\text { and/or diction plug } \\
\text { ins }\end{array}$ & $\begin{array}{l}\text { Allows add-ons of separate plug-ins } \\
\text { that perform translation of type or } \\
\text { audio, or diction. }\end{array}$ & $\begin{array}{l}\text { Provides accessibility to students } \\
\text { who may have sight impairment } \\
\text { or language barriers. }\end{array}$ \\
\hline
\end{tabular}

\section{Proposed Design}

The creative process within this study focused primarily on the app architecture, function inclusion, and functionality, in order to address the needs of the faculty users, and for the needs of the students who will receive the output from the product. The layout and design aesthetic were of less concern in this research, however for the purpose of presenting the prototype solution the researcher developed an initial design aesthetic and branding. The tentative product name is Designgrade and a contemporary colour and graphic design theme inspired by Bauhaus design was developed. The researcher aimed to develop an appealing visual aesthetic that was not particular to the domain of fashion design but would be applicable generally across the creative industries for which it could be used. The general design aesthetic can be seen here on a screenshot of the app landing page in Figure 1. Main screen views were designed to be clear and free to work within the white space, so tool bars were kept to minimal plus sign, back arrow, and menu icons as seen in Figure 2. Figure 3 shows the file organization page, where all documents and templates are accessible, while Figure 4 is the plus menu with all application tools that are ready to use at any time. 


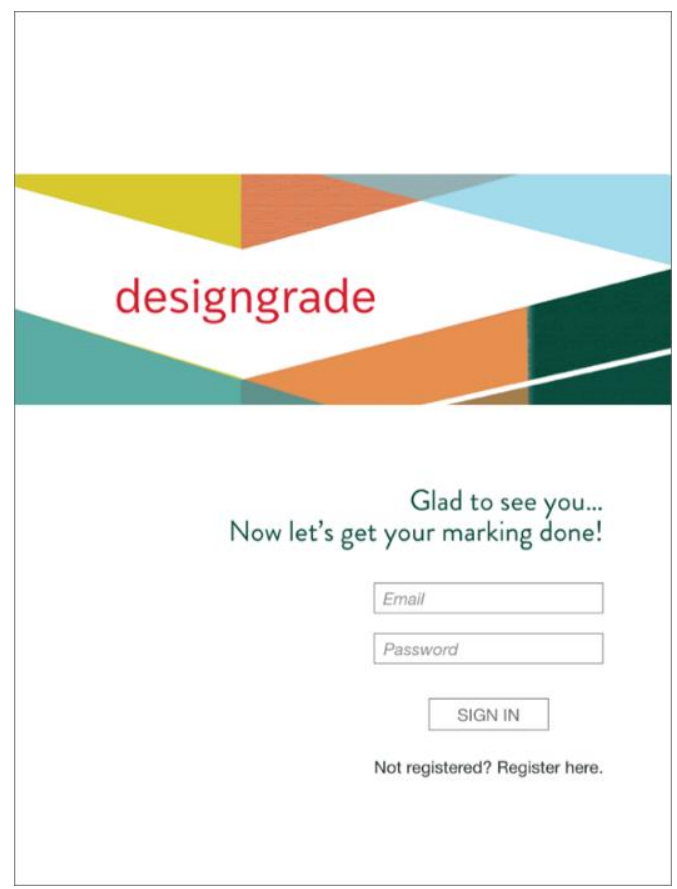

Figure 1. Landing page design.

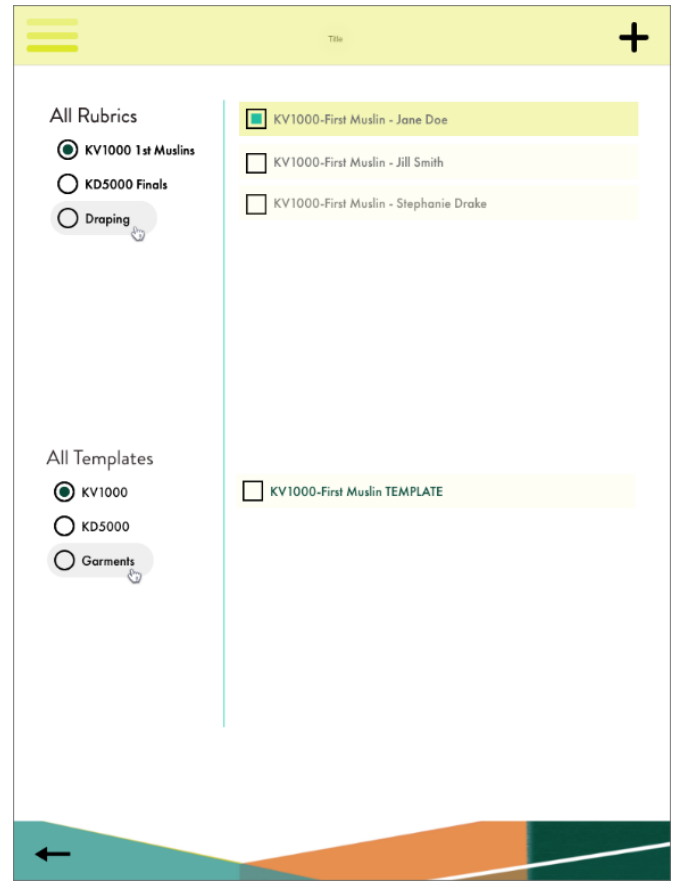

Figure 3. Main file organization.

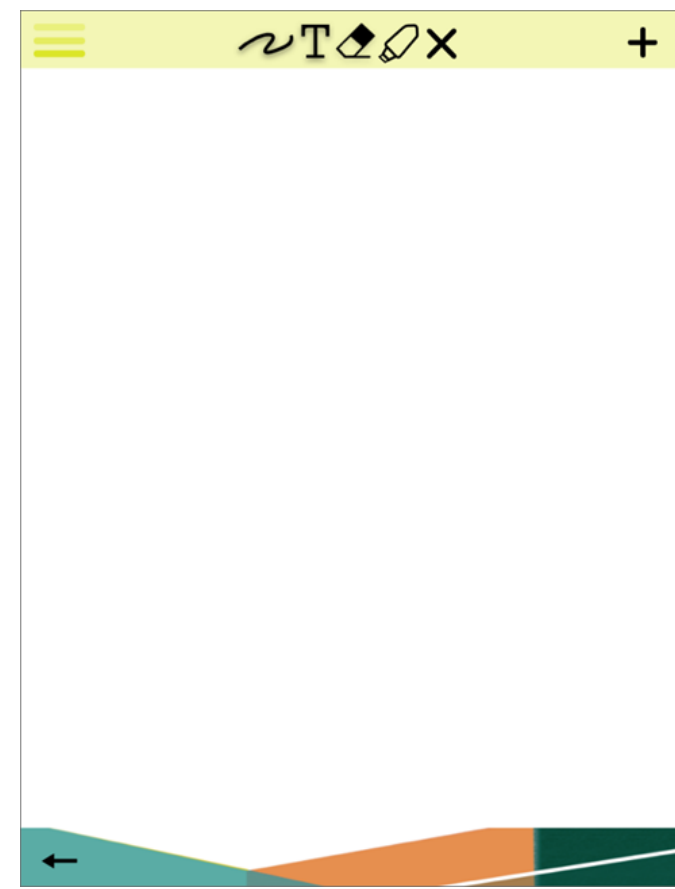

Figure 2. Main working page.

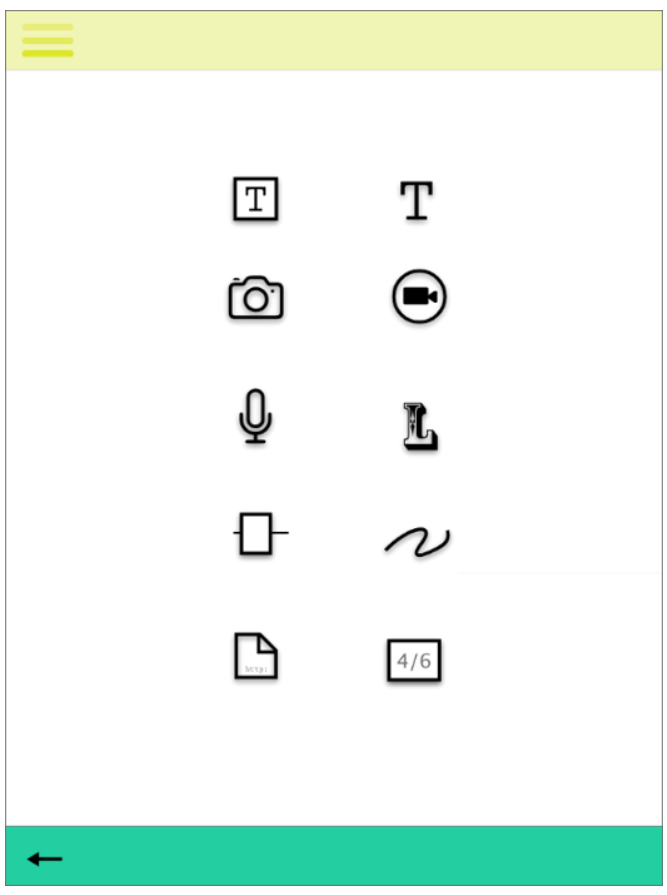

Figure 4. Plus menu screens. 
Time-saving features such as scrolling to add a comment, or sliding to pick the grade are shown in Figures 5 and 6.

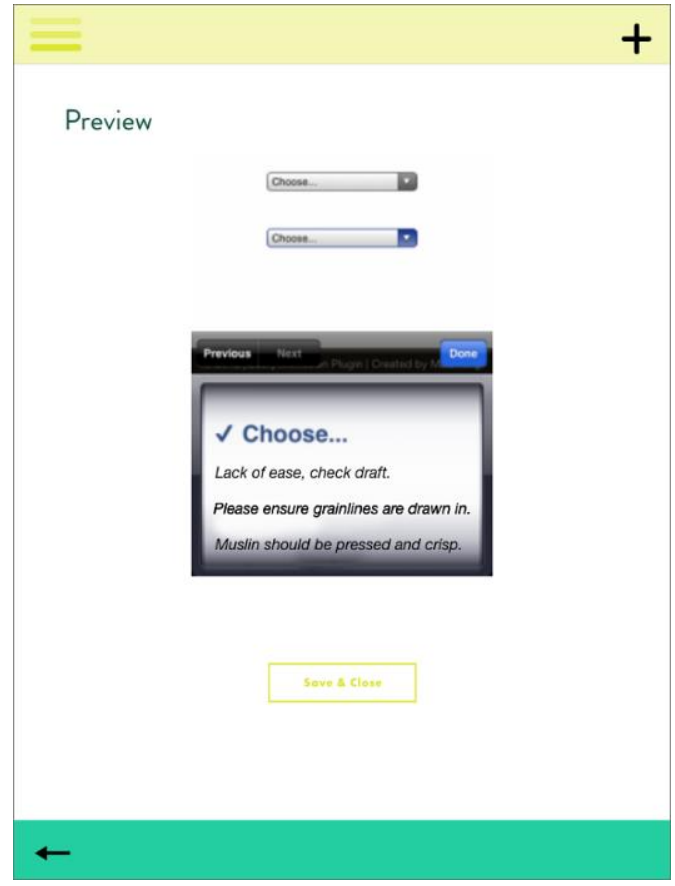

Figure 5. Comment chooser roller-scroll.

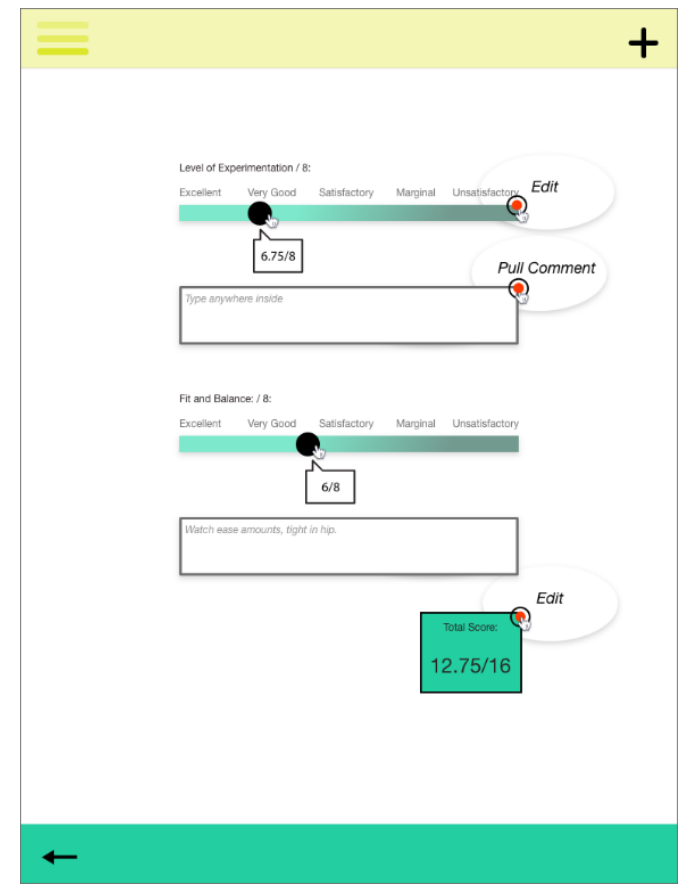

Figure 6. Grade slider with pull-a-comment.

Grade criteria boxes have been carefully planned so that they offer full customization by the user, while step-by-step prompts will walk the user through the set up with ease. The app will have the ability to display weighted grades, bonus points, and deductions, and the user will have the ability to revise or override the final grade. Figure 7 shows an example of a screen that is a part of the user flow in setting up a grade criteria box. 

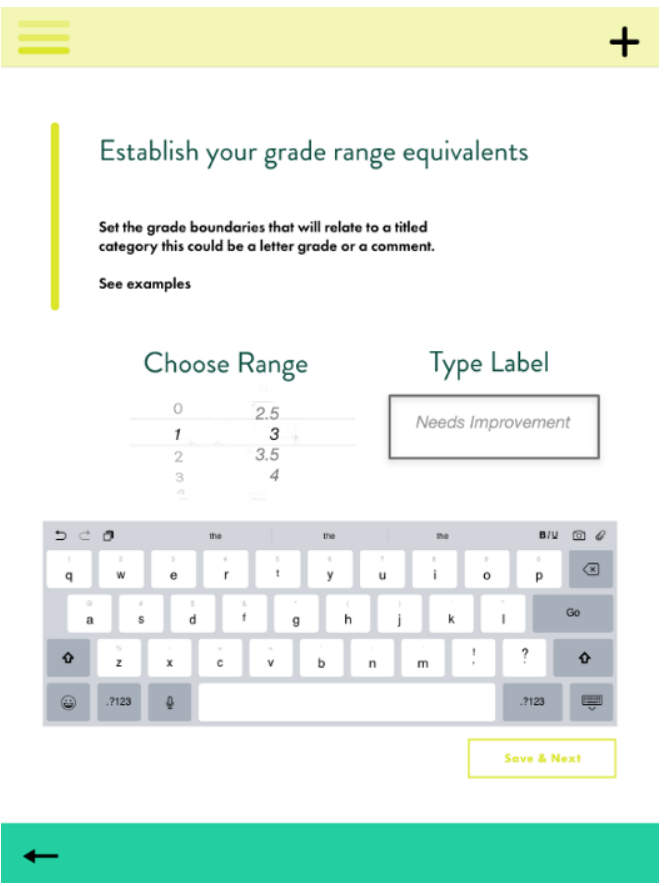

Figure 7. Part of the work flow prompts in setting up grade criteria boxes.

The draw/scribble function allows the user to draw or write over top of a photo or pdf document, and it is expected to be one of the most powerful features of the prototype. Usertesting participants agreed that notating a photo of the work provides additional clarity, and provides a welcomed visual form of communication in a visual field (User-Testing Participant B, personal communication, March 12, 2019; User-Testing Participant A, personal communication, March 14, 2019). For example, one could sketch a new silhouette shape directly on top of the photo of the student's dress design, proposing possible alternative outcomes in a visual form. Exact locations where issues need to be addressed can be pinpointed with the pen by circling, highlighting, or drawing arrows. Figure 8 shows an example of the draw/scribble feature. All completed screenshots included in the prototype stage can be viewed in Appendix D. 


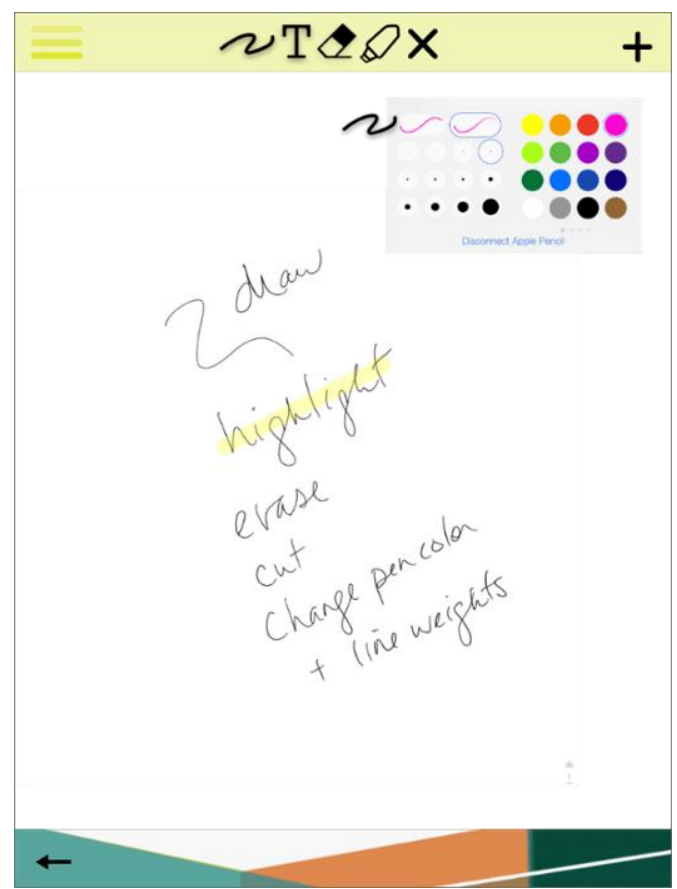

Figure 8. Draw/scribble function used on main screen.

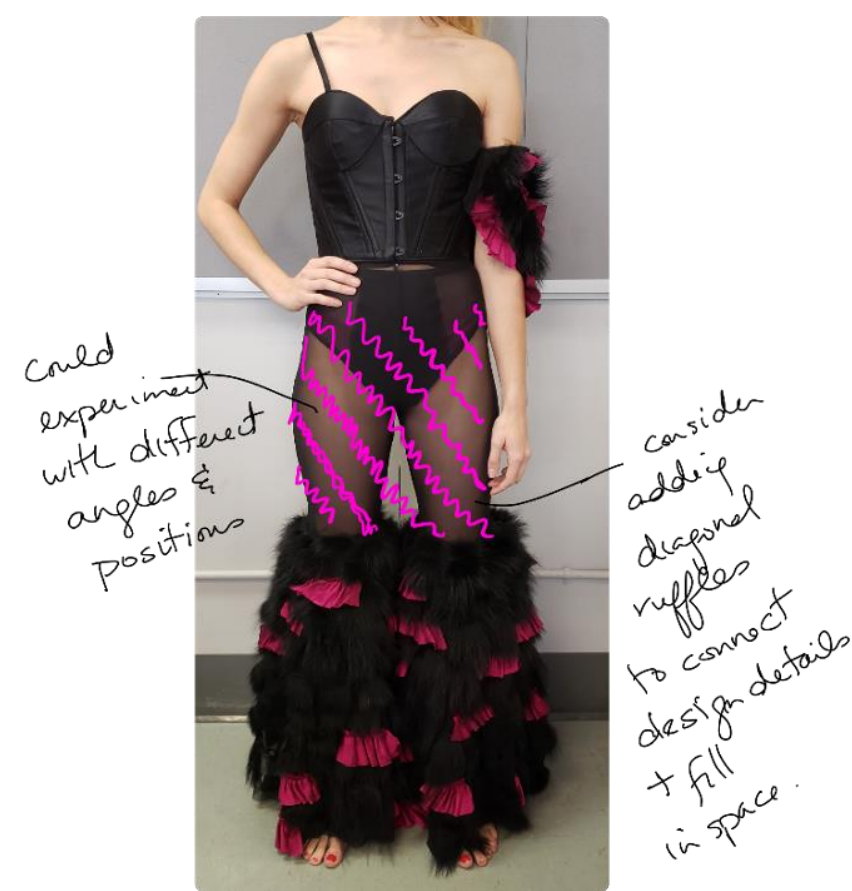

Figure 9. Example of drawing over artifact image. Photo of student work (Samantha Brittany) used with permission.

\section{Development of Pre-Designed Templates}

The app will include a selection of pre-designed generic rubric templates. The researcher understands that not all potential users will be comfortable with setting up their own templates (Faculty Participant B, personal communication, January 3, 2019); others, particularly in the case of contract lecturers, are often subject matter experts rather than academics, and may not be experienced in rubric development. Still others may appreciate having a starting point from which they can edit add and adjust to their liking as a time-saving factor.

When creating an example of a template for this prototype, the researcher leaned on aspects of the literature review and interviews. Key considerations were as follows:

1. The need for formative assessment and effective feedback (Evans, 2013; Spector et al., 2016) was supported by the embedded photos and/or video, and audio, that may more 
successfully capture works in progress. The add a reference link can also support selfdirected learning by pointing students to additional information as they travel through their research process.

2. The need for flexibility and individualization in evaluations and feedback (Bocconi \& Trentin, 2014; Student Participants A \& B, 2018), supported again by the array of feedback formats included that offer specificity to the feedback, and the general verbiage used in criteria descriptions intended to capture the essence of creative research and can better accommodate diversity amongst projects.

3. Understanding the intricacies of assessing creativity put forth by Amabile's Consensual Assessment Technique (Kaufman, Baer, \& Cole, 2009), whereby it is understood that creative and technical aspects are distinguishable from one another and therefore can be separated in assessment criteria, and that though creativity is seen as a subjective attribute, and that those that are experts in a field (instructors likely to be teaching the course) do tend to assess a works creative success similarly (Kaufman et al., 2008), was the backbone for the rubric criteria design on the templates.

Figure 10 shows an example of a rubric output, which is in pdf full colour format, resulting from the use of a pre-designed template included in the app. 


\section{Evaluation Criteria:}

Level of Experimentation / 8 :

Excellent Very Good Satisfactory Marginal Unsatisfactory

Would like to have seen more innovative method for attaching ruffles, they seem a bit disjointed with the flow of the skirt. Love the overall slouchiness achieved and the incorporation of tube-top understructure.

Fit and Balance / 8 :

Excellent Very Good Satisfactory Marginal Unsatisfactory

Outfit is well balanced, just the ruffle details could be reworked to Integrate better with overall fluidity.

No concern with fit

Innovative use of Asymmetry / 4 :

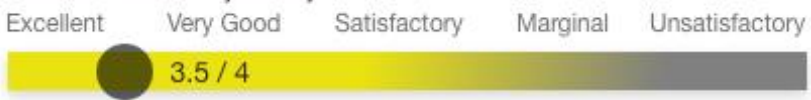

Very successful - as look remains flattering to a body, not forced, feels very natural despite the number of asymmetric elements.

\section{Additional Resources:}

External reference links:

Click here to see tips on applying slastic with cover seamer

Audio:

Audio | 0:05:21/ 0:10:00

Instructor Live Critique Recorded September Jane Smith, Week 5 Critique

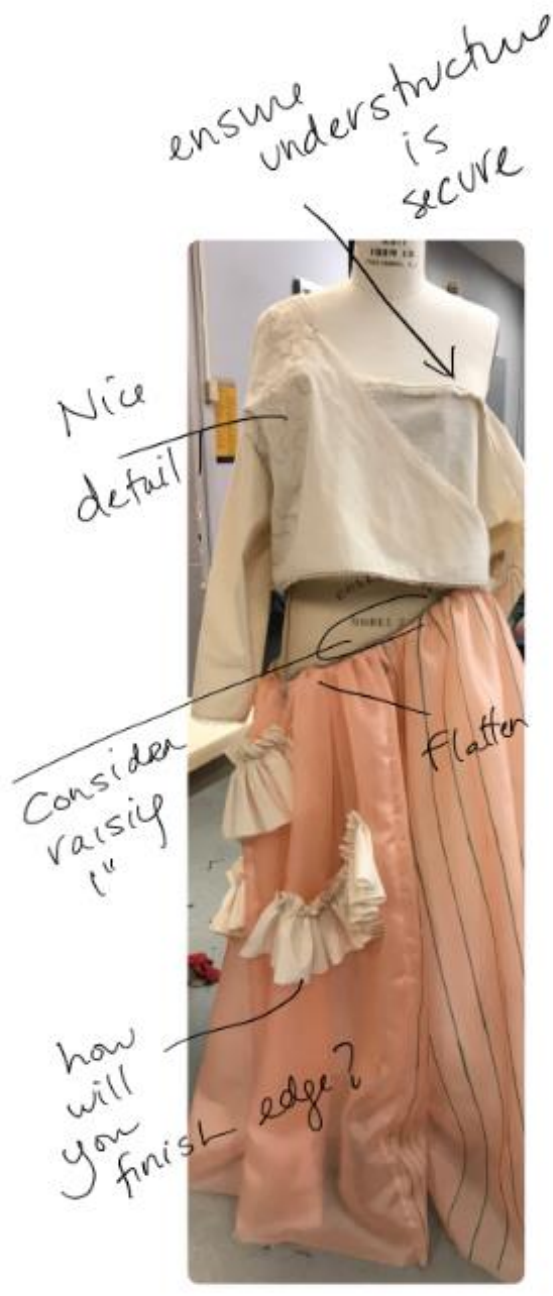

\section{Comments \& Grade:}

Nice project, the slouchy angles felt in both the top and skirt due to the clever use of the sheer mesh inserts and tube top understructure, make this look feel effortless.

Figure 10. Example of student-facing PDF output from one of Designgrade's pre-designed templates. Photo of student work (Mc Pagalan) used with permission. 
This rubric output example highlights the use of some of the key app features discussed, including: notated photo of the critique; the add a photo function; the draw/scribble function; the display of the easy-to-read grade criteria boxes with added comment boxes; and the additional resources added section highlights the add audio recording and add an external link functionality. The example demonstrates the rubric template designer's concerns with accessibility and flexibility for the user, providing clarity for the student via the interactive display, the importance of including a range of feedback elements, and easy-to-interpret grading criteria boxes.

\section{Preliminary User-Testing/Feedback Sessions}

Preliminary user-testing/feedback sessions with two faculty participants and one UX professional gleaned the following significant results:

1. Users supported the general look and feel of the app.

2. Users believed that the time-saving features like slide for a grade or pick a comment would be very useful and effective (User-Testing Participant B, personal communication, March 12, 2019; User-Testing Participant A, personal communication, January 24, 2019).

3. The UX professional noted that an early stage of setting up a rubric would have to be adding affiliating it with the LMS course shell, so that student lists could be downloaded and uploads could associate with correct student, and that security measures would be needed to protect student confidentiality (UX professional participant, personal communication, January 30, 2019).

4. Users strongly believed that the ability to record audio and write over top of pictures would strongly enhance their praxis (User-Testing Participant B, personal communication, March 12, 2019; User-Testing Participant A, personal communication, January 24, 2019).

The two faculty participants were also shown the student-facing example of an output of 
a Designgrade template as shown in Figure 10. Both participants felt that it was an effective layout for students to view (User-Testing Participant B, personal communication, March 12, 2019; User-Testing Participant A, personal communication, March 14, 2019). User-Tester A liked that the notated photo was positioned next to the grading criteria boxes, rather than on an attachment or separate page, as this positioning adds clarity to what is being evaluated. $\mathrm{He} / \mathrm{she}$ also liked the sliding grade view design to present the grade criterion, as he/she believed it was very easy to understand and read (Personal communication, March 14, 2019). 


\section{CHAPTER 7: CONCLUSION}

\section{Study Findings and Contributions}

Based on the early feedback from preliminary user feedback sessions, the app proposes a viable opportunity to improve current praxis in the area of providing feedback and assessment of creative works within HE. The product posits many useful features and technological tools together in one app solution, so that users do not have to use multiple methods and devices, retype their work, et cetera. The time-saving features are expected to be welcomed by potential faculty users, while the multitude of integrated feedback formats at the users' fingertips will engage today's diverse learners with accessible and interactive guidance, provide increased clarity to feedback, and facilitate further learning. Accuracy may improve due to the built-in summation feature, from downloaded class lists, and from the uploading of grades directly to the LMS, while departments will gain by having digitally stored documentation/records of all course feedback and assessment.

The call for graduates who can think divergently can only be satisfied by a change in praxis, one that provides formative assessment on creative process efficiently, effectively, and in alignment with today's social environment.

If feedback and formative feedback is key to learning (Bennett et al., 2017; Evans, 2013), and diverse learners require different approaches (Lippincott, 2010; Roberts et al., 2012), then we must reach our goals by advancing our practices in providing this crucial opportunity for students to learn. As current cohorts embrace digital platforms (Roberts et al., 2012; Faculty Participant A, personal communication, October 16, 2019) and faculty users are constrained by lack of time (Franklin \& Smith, 2015; Faculty Participant B, personal communication, January 3, 2019; Faculty Participant A, personal communication, October 16, 2018), we would be wise to adopt technological tools in our collective practice. The clarity, flexibility, and diverse offering 
of feedback mediums featured in this app will allow users to enrich the feedback and expedite the time frame for which the students will receive feedback, allowing them the chance to implement revisions based on that feedback.

The implications of this study provide the emerging research field of MBA with a conceptual model for a practical tool suitable for fashion and other creative industries in HE that is aligned with contemporary pedagogical frameworks and the needs of today's learners.

\section{Limitations in Scope of Study}

Within the scope of this research, the app prototype has undergone preliminary usertesting only. More rigorous user-testing with more participants should be undertaken in order for design and features to be finalized and coding and further development can begin. Student-facing outputs from the rubric templates should also be reviewed by student participants, as to date only faculty participants have reviewed.

Some of the proposed functionality in the app, including the uploading of grades function, downloading of class lists, or batch uploading feedback rubrics, would require the partnering with LMSs such as D2L and Moodle, and may also be subject to possible approval from the faculty's institution. Though the app is still useful without this ability, the researcher acknowledges that the integration with the school's LMS would greatly optimize the tool.

Lastly, the prototype was developed using Adobe $\mathrm{XD}$, though powerful as a visualization tool, it does not provide full-functionality for testing. The study included preliminary feedback from a UX professional and two faculty participants; however, the feature inclusions have not yet been subject to in-depth feedback and consultation that would take place in an actual development phase. 


\section{CHAPTER 8: FUTURE DIRECTIONS}

1. Opportunities for Product Development: To bring the product to reality, next steps would be to further the design stages by conducting rigorous user-testing and applying resulting refinements to the prototype, after which a professional app developer could be commissioned to code and develop a fully functioning product.

2. Integration with Learning Management Systems: To necessitate the fully functioning vision of the researcher's proposed solution, corporate partnering with HE LMSs would have to be successfully established.

3. Work through Implementation Challenges: Significant capital would be required in order to develop the tool to a fully realized product. Corporate partnerships and institutional approvals would have to be in place, and then the product must be successfully marketed to potential faculty users. The app will also have to encompass a high degree of security measures in its architecture in order to satisfy student privacy and ethics requirements (UX professional participant, personal communication, October 16, 2018). The researcher has not yet studied the requirements and possible implementation issues that may result from these necessary measures.

4. Emerging Field of Mobile-Based Assessment: When conducting the literature review it was apparent how little was studied in the area of using technology within assessment in HE. Considering that fashion and other creative industries are often at the forefront of innovation, it is surprising that assessment and feedback praxis has not largely embraced technological solutions to date. If Designgrade and other mobile solutions were to be made available to faculty, further research into their implementation and success of use could be studied. 


\title{
Appendix A: Excel Breakdown of Initial App Architecture
}

\author{
Landing Page \\ Sign in, set up a sign in (add other necessary screens, this app will be a paid download, but sign in will help with security behind students grade info?? \\ Choose Options \\ Create New (button) \\ Set up a Rubric this would save as a template to start your marking with, can still add as you go \\ Name the Rubric \\ Place a Logo/Image \\ Draw Graphic Lines \& Boxes pencil and or line tool, 3 weights to choose from, edit size from corner drag \\ Set up Evaluation Criteria Boxes - as soon as one box is set up automatically a totals box appears \\ Add a Type box could also be used for comment box \\ Add a comment box that also has a drop downlist of pre-set comments \\ pink is part of a Add a photobox/add a photo really just a box border, that when pass over the camera icon comes up to take a pic or add pic from file \\ main + menu of $\quad$ Add a recording box, add a recording \\ functions Write/scribble - pen tool with color and weight chooser, to draw anywhere on page \\ Save Rubric Template \\ Name file choose folder \\ Send /Share - ability to upload to various drive options or email pdf file apple airdrop \\ Use a Blank Page this would startwith a blank page but still has all the same options to use and edit \\ Place a Logo/Image \\ Draw Graphic Lines \& Boxes pencil and or line tool, 3 weights to choose from, edit size from corner drag \\ Set up Evaluation Criteria Boxes - as soon as one box is set up automatically a totals box appears \\ Add a Type box could also be used for comment box \\ Add a comment box that also has a drop downlist of pre-set comments \\ Add a photobox/add a phi really just a box border, that when pass over the camera icon comes up to take a pic or add pic from file \\ Add a recording box, add ; audio recorder icon \\ Write/scribble - pen tool with color and weight chooser, to draw anywhere on page \\ Save \\ Name file choose folder \\ Send /Share - ability to upload to various drive options or email pdf file apple airdrop \\ Upload Grade to D2L \\ Upload Evaluation Sheet to D2L \\ Open Existing (button) \\ File list to pick file \\ once file is open, all the same choices on the plus menu would be given with the plus sign \\ user can interact with any of the items, can adjust grades with the sliders etc. \\ Place a Logo/Image \\ Draw Graphic Lines \& Boxes \\ Set up Evaluation Criteria Boxes - as soon as one box is set up automatically a totals box appears \\ Add a Type box \\ Add a comment box that also has a drop downlist of pre-set comments \\ Add a photobox/add a photo \\ Add a recording box, add a recording \\ Write/scribble - pen tool with color and weight chooser, to draw anywhere on page \\ Save, Save As \\ Name file choose folder \\ Send /Share - ability to upload to various drive options or email pdf file apple airdrop \\ Upload Grade to D2L \\ Upload Evaluation Sheet to D2L
}




\section{Appendix B: Example of Function Breakdown in Excel}

\section{Set Up Evaluation Criteria Boxes}

1) Title and/or Description

keyboard pops up and text box, type name, simple formatting menu for type size Italic, Bold save

Edit button when click on title, prompts the reopening of Title and/or Description Box wi1 save

2) Criteria Total Value

numbered keyboard comes up to type in criteria value

save or back

3) Choose number of grade point options

drop down menu comes up where you select number of grade points

save or back

5) Establish your grade point ranges

Criteria box with columns pops up with numbered keyboard

hovering over box calls user to input flashing numbers with numberpad keyboard

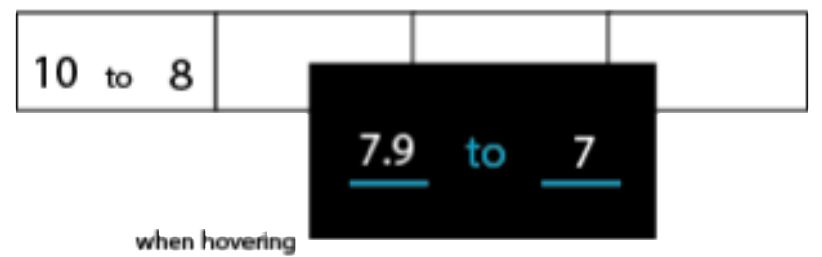

over any box, expanded box pops

up with number space flashing and

numbered keypad ready to punch in

the numbers appearing in white. Click enter

6) Establish your grade point Titles

places it in to the box

Established Criteria box pops up with sliders generated from ranges inputed earlier, top lab€ expand when pass over ready to enter label, keyboard pops up

\begin{tabular}{|c|c|c|c|}
\hline Edit Title & Edit Title & Edit Title & Edit Title \\
\hline $\begin{array}{rr}7.9 & 7 \\
\end{array}$ & 6.96 & & \\
\hline
\end{tabular}

7) Add a comment box

choose style (drop down menu comes up to choose)

Brief comment

Standard

Elaborate comment

Box appears in the size chosen, a flashing title "Edit Title" appears

save or back

edit 
Appendix C: Screenshot of Early Design Stages in Adobe XD

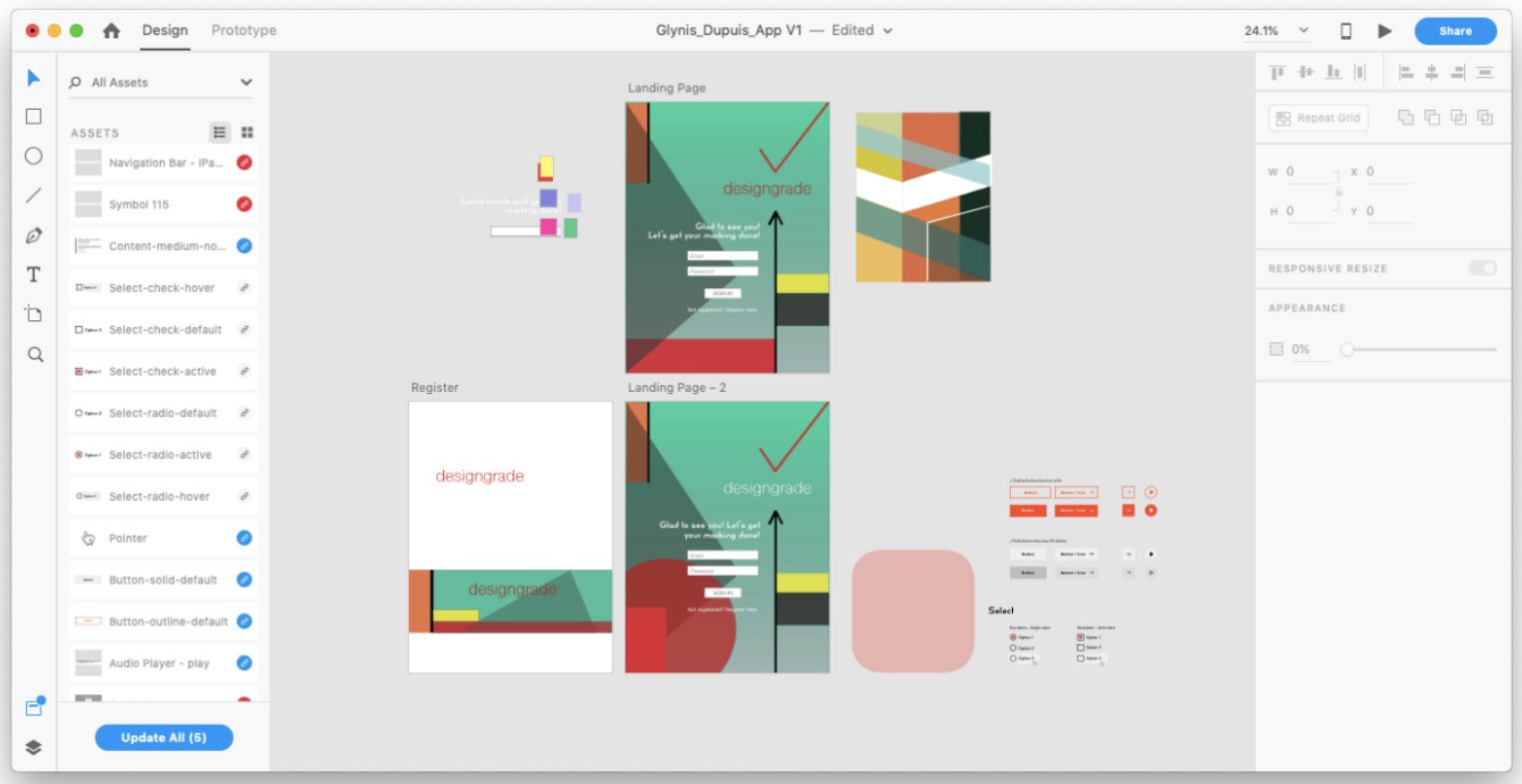




\section{Appendix D: Designgrade Prototype Screens}
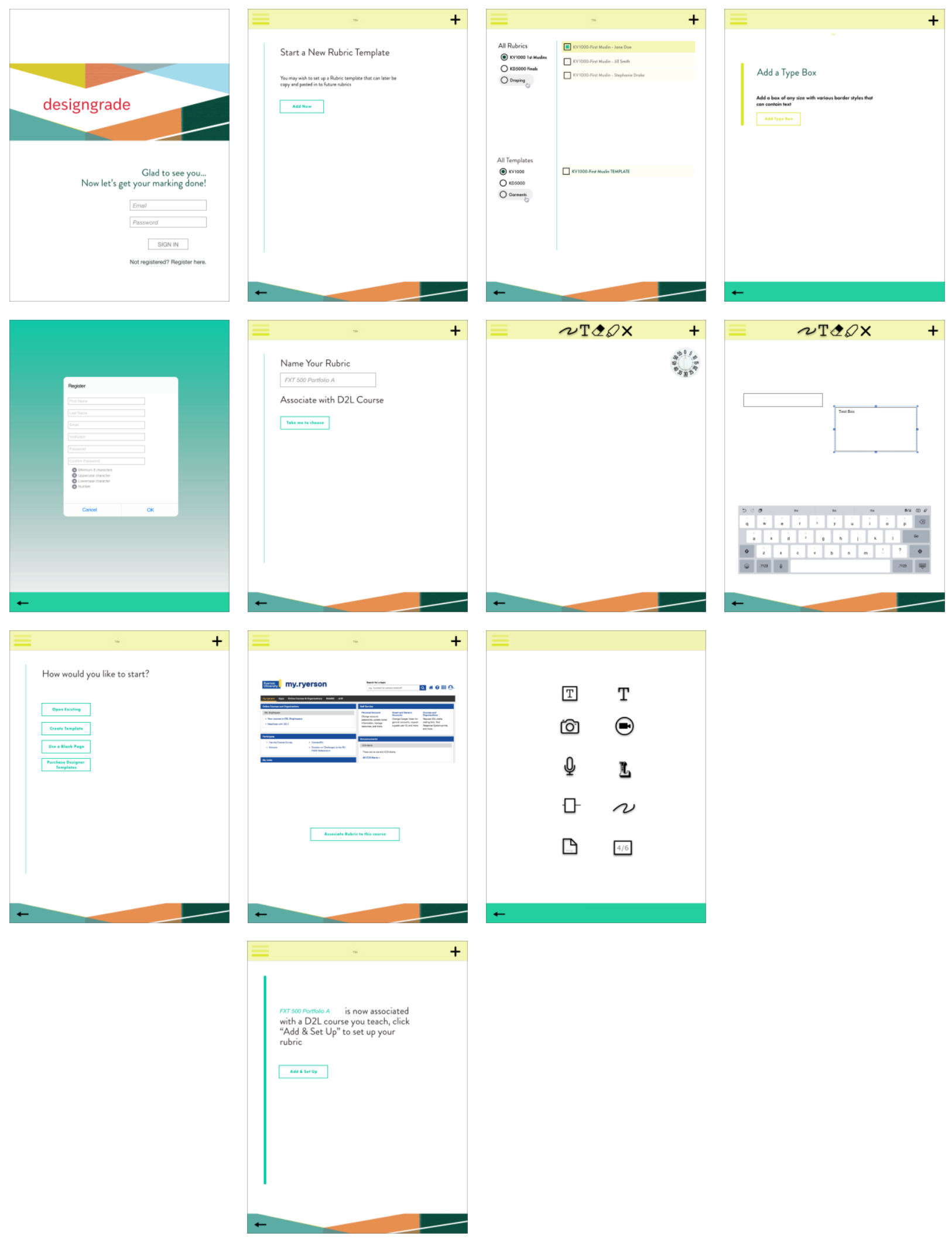

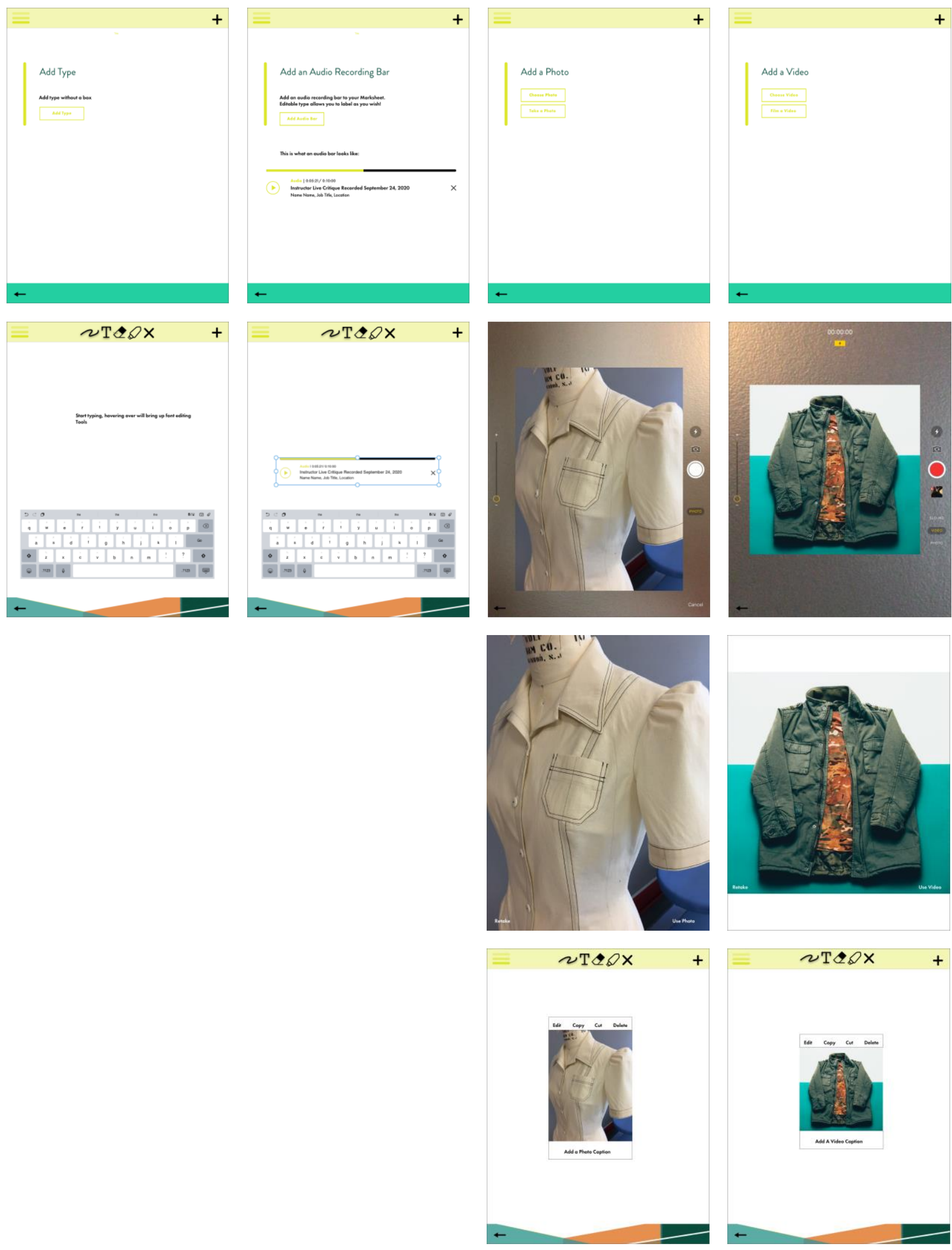


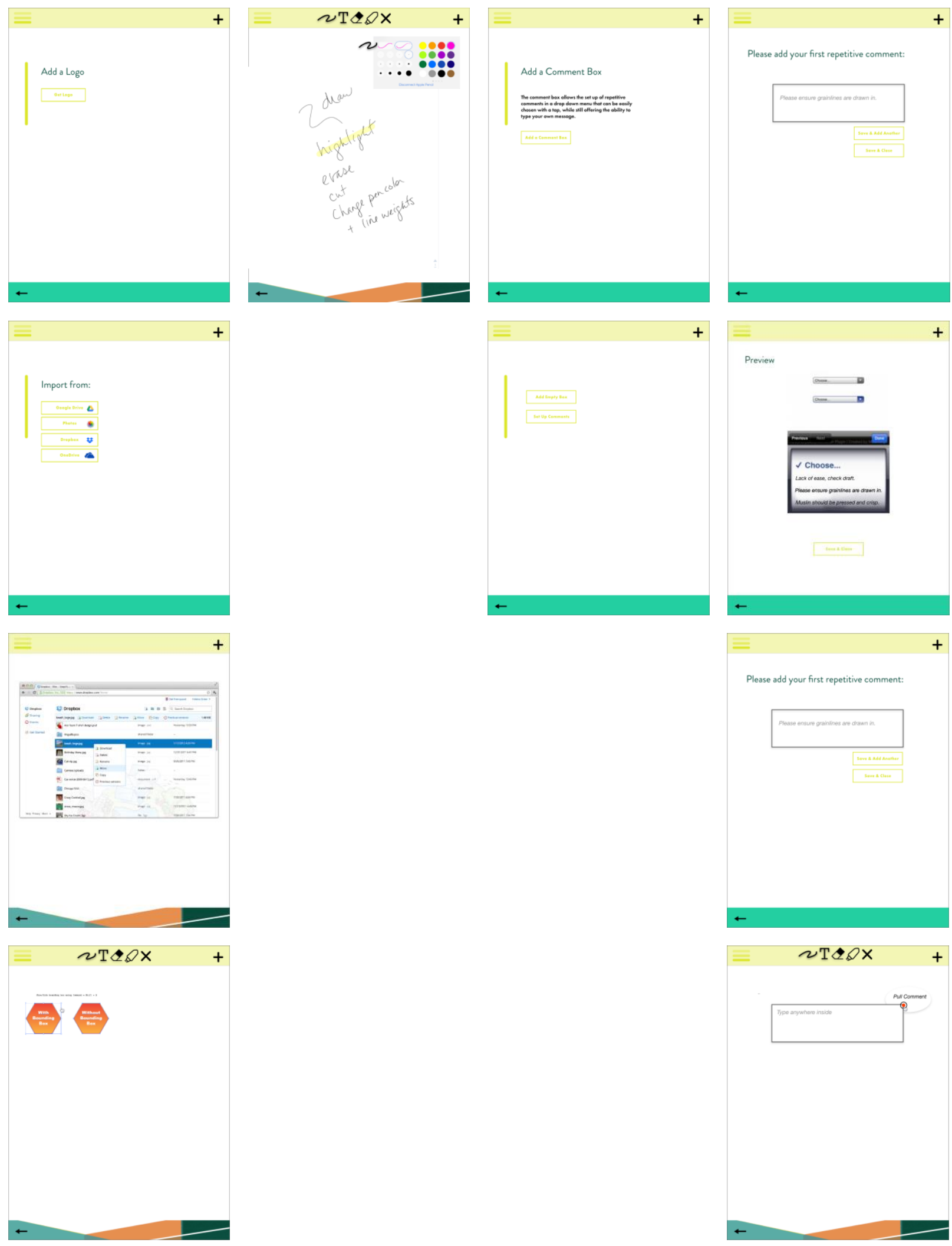




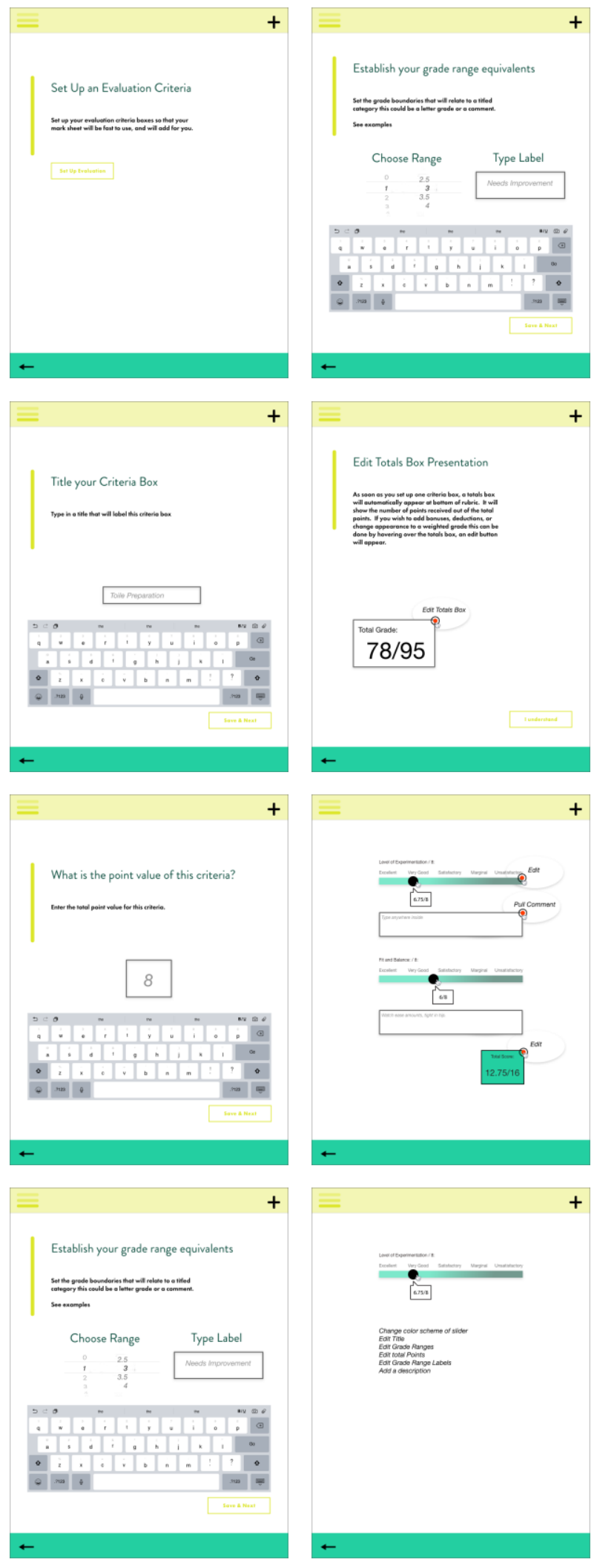




\section{References}

Archer, J. C. (2010). State of the science in health professional education: Effective feedback. Medical Education, 44(1), 101-108. doi:10.1111/j.1365-2923.2009.03546.x

Atkinson, D., \& Lim, S. L. (2013). Improving assessment processes in higher education: Student and teacher perceptions of the effectiveness of a rubric embedded in a LMS. Australasian Journal of Educational Technology, 29(5), 651-656. doi:10.14742/ajet.526

Baer, J., \& McKool, S. S. (2009). Assessing creativity using the consensual assessment technique. In C. Schreiner (Ed.), Handbook of research on assessment technologies, methods, and applications in higher education (pp. 65-77). Hershey, PA: IGI Global. doi:10.4018/978-1-60566-667-9.ch004

Bennett, S., Dawson, P., Bearman, M., Molloy, E., \& Boud, D. (2017). How technology shapes assessment design: Findings from a study of university teachers. British Journal of Educational Technology, 48(2), 672-682. doi:10.1111/bjet.12439

Bill, A. (2012). "Blood, sweat and shears": Happiness, creativity, and fashion education. Fashion Theory, 16(1), 49-65. doi:10.2752/175174112X13183318404186

Bocconi, S., \& Trentin, G. (2014). Modelling blended solutions for higher education: Teaching, learning, and assessment in the network and mobile technology era. Educational Research and Evaluation, 20(2009), 516-535. doi:10.1080/13803611.2014.996367

Braun, L. W. (2016, May 31). Using design thinking: Providing a framework for youth activities. American Libraries. Retrieved from https://americanlibrariesmagazine.org/2016/05/31/using-design-thinking/

Brydges, T., Hracs, B. J., \& Lavanga, M. (2018). Evolution versus entrenchment: Debating the impact of digitization, democratization, and diffusion in the global fashion industry. International Journal of Fashion Studies, 5(2), 365-372. doi:10.1386/infs.5.2.365_7 
The Business of Fashion and McKinsey \& Company. (2017). The state of fashion 2018. Retrieved from https://cdn.businessoffashion.com/reports/The_State_of_Fashion_2018_v2.pdf

DeBard, R. (2004). Millennials coming to college. New Directions for Student Services, 2004(106), 34-45. doi:10.1002/ss.123

Dunphy, K., Mullane, S., \& Allen, L. (2016). Developing an iPad app for assessment in dance movement therapy. Arts in Psychotherapy, 51, 54-62. doi:10.1016/j.aip.2016.09.001

Evans, C. (2013). Making sense of assessment feedback in higher education. Review of Educational Research, 83(1), 70-120. doi:10.3102/0034654312474350

ForAllRubrics [Computer software]. Chicago, IL: Forall Systems, Inc.

Franklin, R., \& Smith, J. (2015). Practical assessment on the run-iPads as an effective mobile and paperless tool in physical education and teaching. Research in Learning Technology, 23(2015). doi:10.3402/rlt.v23.27986

Freeman, C., Son, J., \& McRoberts, L. B. (2015). Comparison of novice and expert evaluations of apparel design illustrations using the consensual assessment technique. International Journal of Fashion Design, Technology and Education, 8(2), 122-130.

doi:10.1080/17543266.2015.1018960

FreshGrade [computer software]. Kelowna, BC: FreshGrade.

Gobble, M. M. (2014). Design thinking. Research Technology Management, 57(3), 59-62. doi: $10.5437 / 08956308 \times 5703005$

Im, H., Hokanson, B., \& Johnson, K. K. P. (2015). Teaching creative thinking skills: A longitudinal study, 33(2), 129-142. doi:10.1177/0887302X15569010 
Jeffries, K. K., Zamenopoulos, T., \& Green, A. J. K. (2018). Design creativity, technical execution and aesthetic appeal: A cat with caveats (Part 2). International Journal of Design Creativity and Innovation, 6(1-2), 66-79. doi:10.1080/21650349.2017.1381043

Kaizena [Computer software]. San Francisco, CA: Kaizena, Inc.

Karpova, E., Marcketti, S., \& Barker, J. (2011). Putting the puzzle together: Apparel professionals' perspectives on creativity . International Journal of Fashion Design, Technology and Education, 4(2), 103-113. doi:10.1080/17543266.2010.542185

Kaufman, J. C., Baer, J., \& Cole, J. C. (2009). Expertise, domains, and the Consensual Assessment Technique. The Journal of Creative Behavior, 43(4), 223-233. doi:10.1002/j.2162-6057.2009.tb01316.x

Kaufman, J. C., Baer, J., Cole, J. C., \& Sexton, J. D. (2008). A comparison of expert and nonexpert raters using the consensual assessment technique. Creativity Research Journal, 20(2), 171-178. doi:10.1080/10400410802059929

Kemmis, S. (2009). Action research as a practice-based practice. Educational Action Research, 17(3), 463-474. doi:10.1080/09650790903093284

Lippincott, J. K. (2010). Information commons: Meeting millennials' needs . Journal of Library Administration, 50(1), 27-37. doi:10.1080/01930820903422156

Malcolm, M. P., \& Roll, M. C. (2017). The impact of assistive technology services in postsecondary education for students with disabilities: Intervention outcomes, use-profiles, and user-experiences . Assistive Technology, 29(2), 91-98.

doi:10.1080/10400435.2016.1214932

Nikou, S. A., \& Economides, A. A. (2018). Mobile-based assessment: A literature review of publications in major referred journals from 2009 to 2018. Computers and Education, 125, 101-119. doi:10.1016/j.compedu.2018.06.006 
P21: Partnership for 21st Century Learning. (2019). Framework for 21 st century learning. Retrieved from http://www.battelleforkids.org/networks/p21/frameworks-resources Radclyffe-Thomas, N. (2015). Fashioning cross-cultural creativity: Investigating the situated pedagogy of creativity. Psychology of Aesthetics, Creativity, and the Arts, 9(2), 152-160. doi:10.1037/aca0000014

Raphelson, S. (2014, October 6). From GIs to Gen Z (or is it iGen?): How generations get nicknames. npr. Retrieved from http://www.npr.org/2014/10/06/349316543/don-t-labelme-origins-of-generational-names-and-why-we-use-them

Razzouk, R., \& Shute, V. (2012). What is design thinking and why is it important? Review of Educational Research, 82(3), 330-348. doi:10.3102\%2F0034654312457429

Roberts, D. H., Newman, L. R., \& Schwartzstein, R. M. (2012). Twelve tips for facilitating millennials' learning. Medical Teacher, 34(4), 274-278. doi:10.3109/0142159X.2011.613498

Samuels-Peretz, D., \& Powers, J. (2014). Documentation and universal instructional design: A partnership supporting diverse learners in higher education. New Educator, 10(1), 35-43. doi:10.1080/1547688X.2014.868222

Seesaw [Computer software]. San Francisco, CA: Seesaw Learning, Inc.

Seidel, V. P., \& Fixson, S. K. (2013). Adopting design thinking in novice multidisciplinary teams: The application and limits of design methods and reflexive practices. Journal of Product Innovation Management, 30(Suppl 1), 19-33. doi:10.1111/jpim.12061

Sesame [Computer software]. Toronto, ON: Sesame HQ Inc.

Spector, J. M., Ifenthaler, D., Sampson, D., Yang, L. (J.), Mukama, E., Warusavitarana, A., ... Gibson, D. C. (2016). Technology enhanced formative assessment for 21 st century 
learning. Journal of Educational Technology \& Society, 19(3), 58-71. Retrieved from https://www.researchgate.net/publication/305161696

The University of Texas at Austin, Faculty Innovation Center. (2019). How to teach: Divergent thinking. Retrieved from https://facultyinnovate.utexas.edu/sites/default/files/TeachingGuide_HowtoTeachDiverge ntThinking.pdf 